AECU -3374

\title{
DYNAMIC LOADING OF RUPTURE DISCS
}

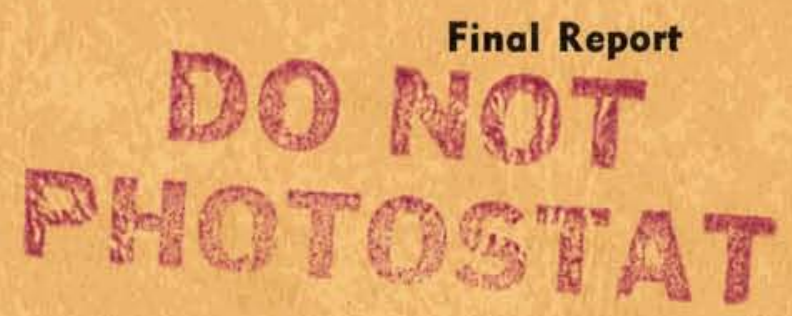

Subcontract No. 548 under

W-7405-eng-26 


\section{DISCLAIMER}

This report was prepared as an account of work sponsored by an agency of the United States Government. Neither the United States Government nor any agency Thereof, nor any of their employees, makes any warranty, express or implied, or assumes any legal liability or responsibility for the accuracy, completeness, or usefulness of any information, apparatus, product, or process disclosed, or represents that its use would not infringe privately owned rights. Reference herein to any specific commercial product, process, or service by trade name, trademark, manufacturer, or otherwise does not necessarily constitute or imply its endorsement, recommendation, or favoring by the United States Government or any agency thereof. The views and opinions of authors expressed herein do not necessarily state or reflect those of the United States Government or any agency thereof. 


\section{DISCLAIMER}

Portions of this document may be illegible in electronic image products. Images are produced from the best available original document. 
This report was produced under a sponsored contract. The conclusions and recommendations expressed are those of the Author(s) and are not necessarily endorsed by the Sponsor. Reproduction of this report, or any portion thereof, must bear reference to the original source and Sponsor.

\section{SYRACUSE UחIVERSITY RESEARCH INSTITUTE}

Approved by:

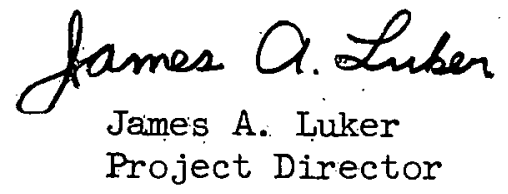

S.U.R.I: Report No.
Sponsored by:

Union Carbide and Nuclear Corporation

Subcontract No. 548 Under $W-7405-e n g-26$

Date:

July 3I, 1956

Ch.E。 273-567F5 
Table of Contents.

SUMMARY . . . . . . . . . . . . . . . . . . . . . . . . . . . . . . . . .

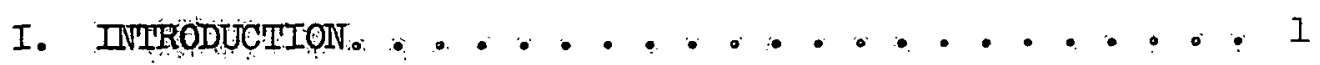

II. APPARATUS, . . . . . . . . . . . . . . 27

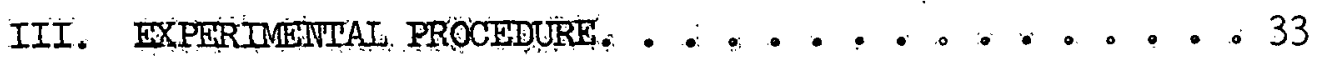

IV. RESUITS. . . . . . . . . . . . . . . 39

V. DISCUSSION OF RESULTS . . . . . . . . . . . . . 45

VI. COHCLUSIONS. . . . . . . . . . . . . . . 48 APPEDDICES:

A. EXPERTEMTAL DATA. . . . . . . . . . . . 49

B. DETERMINATION OF THE THEORETTCAL

RETIECTED WAVE (DETONATION) PRESSURE . . . . . . . 58

C. RUPTURE DISCS - BEFORE AND AFTWER A

DETONATION . . . . . . . . . . . 63

D. COMPOSITION AND MECHANICAL PROPERTIES OF STATIVESS STIEEL-TYPE 304, PHOSPHOR BRONZE, NICKEL, AND,COLD-ROLLED STEEL. . . . . . . . . 67

BIBLIOGRAPHY. . . . . . . . . . . . . 69 
List of Tables and Figures

page

Figure 1. BURSTING PRESSURE OF ALUMIINUM FOIL RUPTURE DISCS vS TEMMPERATURE. . . . . . . 4

Figure 2. CALIBRATION CURVE - THICKITESS OF COPPER DISCS VS BUTRSTIIVG PRESSURE . . . . . . 6

Table I. EXPERIMENTAL DATA OBTAIIED BY CAMPBELL. . . . 6

Table II. EXPERTMENTAL DATA OBTATIED BY STEWART . . . 。 7

Figure 3. BURSTILING PRESSURE vS DISC THICKIESS FOR 2S-0 ALUMTINUM . . . . . . . . . . . . 9

Figure 4. ILEUMANN BANDS FORMED BY IMPACT IN IRON AND ALLOYED FTRRITES . . . . . . . . . I2

Figure 5. SHEAR STRESS VS SHEAR STRATH FOR VARIOUSS METALS. . . . . . . . . . . .... 13

Figure 6. STRATI-HARDENIIIG II ALUMTINUM. . . . . . . 14

Figure 7. A DISLOCATION IN A CRYSTTAL. . . • . . . . 17

Figure 8. RELATIONSHIP BETWEEN RESISTANCE TO SLIP AND FINENESS OF THE MTCROSTRUCTURE IN STLEET . . 20

Figure 9. STRAIN-HARDEIVING IN Mg CRYSTALS AT DIFHERENT TEMPERATURES. . . ........ 22

Figure 10. STRATIT-HARDEIIITG IN AI CRYSTAIS AT DIFFERENT TEMPERATURES. . . . . . . . . 23

Figure 11. STRESS vS STRAIN FOR VARIOUS STAINLESS STTEELS AS A FUNCTION OF NICKEL CONPLENT. . . . 24

Table III. STATIC RATING OF RUPTURE DISCS. . . . . . . 29

Figure 12. RUPTURE DISC APPARATUS. . . . . . . . . 3 I Figure 13. FILIING SYSTEM。 . . . . . . . . . 32 


\section{II}

Lis.t of Tables and Figures (Con ${ }^{*}$.)

. Table IV. DEULERMIIATION OF THE THEORETICAL DYNAMIC ULTTMATTE STRESS. . . . . . . . . 40

Table V. DETHRMINATION OF THE EFFECT OF STMPIE .WORK-HARDEINING UPON THE THEORETICAL DYNAMIC

UETIMATE STRESS. . ............ 41

Table VI. DETHRMINATION OF THE FFFECT OF DOUBIE WORK-HARDENING UPON THE THEORETICAL DYNAMTC ULTTMATE STRESS. . . . . . . . . . . 41

Figure 14. DYMAMIC ULTIMATE STRESS VS RUPTUURE DISC RATING (FXPERIMENTAL DATA)。........ 42

Figure 15: TNITIAL GAS PRESSURE vS RUPTURE DISC RATING (EXPERIMENTAL DATA). . . . . . . 43

Figure 16. EFFECT OF WORK-HARDENIIVG UPON THE DYNAMIC ULTIMATE STRESS OF STAINLESS STEEL 304. •. • 44

Table VII. EXPERTMENTAL DATA: THEORETICAL DYMAMIC ULTIMATE STRESS AND EFFECT OF WORK-HARDEIVIMT UPON THEORETICAL DYNAMTC ULTTMATE STRESS. . . . 49

Figure 17. THEORETICAL TICIDEIVT WAVE PRESSURE vS INITIAL GAS PRESSURE. ...........6I

Figure 18. FTVAL THEORETICAL DETONATION PRESSURE .vS INITIAL GAS PRESSTURE. .......... 62

Figures 19

-30 RUPTURE DISCS. ............. 64 


\section{Summary}

Because of the nature of some new processes in modern industry, the study of the effects of gaseous detonations upon certain materials has become very important. This investigation concerns two aspects of the overall problem of gaseous detonations in reactor vessels and components.

Initially, the theoretical dynamic ultimate yield stress was studied and compared with the static ultimate yield stress of stainless steel-type 304 , nickel, phosphor bronze, and cold-rolled steel. Secondly, the effect of work-hardening upon the dynamic ultimate yield stress was determined for these four metals.

The metals used were in the form of commerciallyproduced one (1) inch rupture discs. Each set of discs was rated by the manufacturer, and the ratings were considered as the static ultimate yield stress.

The dynamic loading of the discs was produced by the detonation of a stoichiometric mixture of hydrogen and oxygen in a shock tube. The discs were placed at the end of the tube perpendicular to the path of the detonation shock wave.

The results of this study led to the following conclusions:

(1) The ratio of the theoretical dynamic ultimate yield stress (see Appendix B) to the rupture disc rating (static ultimate yield stress) was greater than one (1) for all four materials. 
(2) The relationship between the theoretical dynamic ultimate yield stress and the rupture disc rating was linear with a correlation coefficient of 0.998 . for stainless steel-type 304.

(3) Of the four materials tested, only phosphor bronze did not dynamically work-harden: 


\section{Introduction}

A. Background

During the last century large groups of engineers and scientists have investigated the properties of materials under stress. The greatest portion of these studies has been done in the field of static loading, as can be seen from the vast amount of articles and books that haye been published in this field.

In the field of strength of materlals, definite conclusions have been stated and the properties of most materials have been defined completely when the materials are subjected to a static stress. The properties of the materials that have been defined are the proportional limit, the elastic limit, the yield point; and the ultimate.stress; thus, the stress-strain diagram of most structural materials is now known.

Since the majority of the work has been confined to the determination of static stress properties of materials, there is at this time comparatively little known concerning the dynamic loading of materials. Although some work has been done on impact loading in the past two decades, there is still another area in this field, that of transient loading. Transient loading is concerned with dynamic loading, when the load is applied and released in microseconds. There has been litțle, if any, research done on the strength of materials under this type of loading. Transient loading of this type may be produced by a gaseous detonation. The subjection of a 
material to an instantaneous load gives rise to many problems concerning the strength of materials.

Since the beginning of recorded history, men have searched for sources of power to lighten their loads for them. As fossil fuels are now rapidly becoming depleted and with the advent of atomic energy, a new source of power is beginning to take its place as an integral part of industry. The heart of this new source is the nuclear reactor. As a result of this, many different types of reactors have been designed and built. One of the most important developments in the race to supply comparatively cheap electrical power is the homogeneous reactor which is still in the experimental stage. Two of the essential elements in a reactor are the fuel and the moderator. In a homogeneous reactor both of these elements are combined in one phase which in this case is an aqueous solution of 93\% enriched uranyl sulfate. As fission occurs, a mixture of hydrogen; oxygen, and steam, which may be detonable, is produced by radiation decomposition. Because of the possibility of a gaseous detonation, the problem of designing a reactor to withstand such a shock is of paramount importance. Presently, work is being done on the dampening of shock waves produced by such a detonation as one possible solution of reactor design. If this study of dampening does not provide the answer to the problem of design, the materials to be used must be mechanically strong to resist the shock wave. 
Therefore, the study of the strength of materials subjected to a dynamic load must furnish the answer.

Any material will fracture when a stress equal to the upper yield stress is applied: The ultimate stress of many materials has been determined statically. As the upper yield stress is an important property of a materialy it is necessary to find its. equivalent; the upper dynamic yield stress, under transient loading. Mann and White (16, 24) concluded that the upper yield stress under dynamic loading was greater than under static loading. One reason given for this conclusion was that specimens under impact exhibit greater ductility and can therefore be deformed to a greater extent before fracture occurs. From theșe facts and conclusions, it followed that a material subjected to a transient load should exhibit greater work-hardening and be more resistant to fracturing than one subjected to a static load.

B. The Use of Rupture Discs in Loading Studies

Murphy (18) was one of the first men to explore the uses. of rupture discs in industry. By rupturing discs, Murphy developed a relationship between the bursting pressure of a disc and the temperature at which rupture takes place. This relationship is shown in Figure 1.

Murphy recommended that in commercial practices the operating pressure should be one-half the bursting pressure of the disc for highly pulsating pressures or impact pressures. 


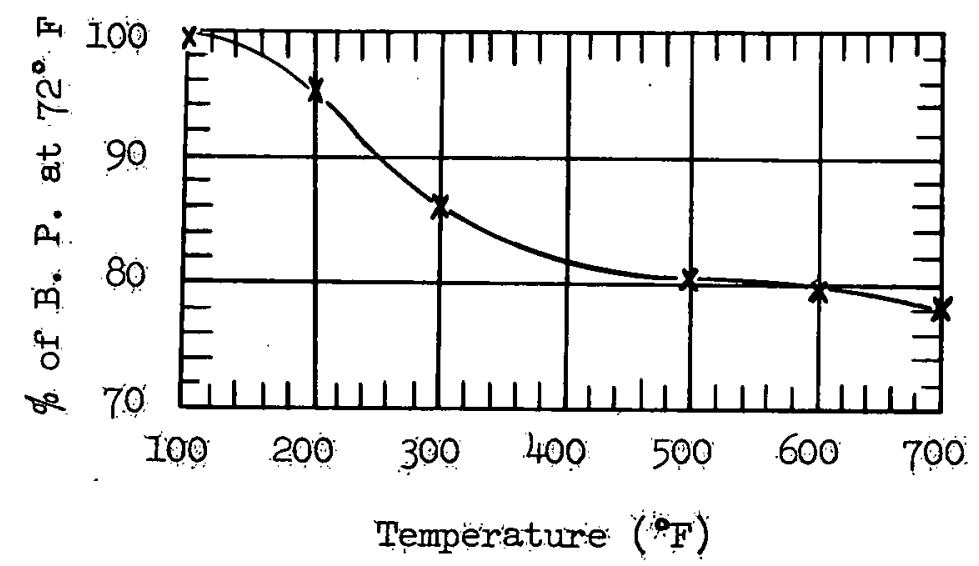

Figure 1

Bursting Pressure of Aluminum Foil Rupture Discs vs Temperature

Murphy (I8)

Commercially available rupture discs are guaranteed to burst within $\pm 5 \%$ of the rated pressure. Out of every batch of discs produced, a representative sample is tested to destruction. If the discs tested rupture with the prescribed range, the appropriate rating is given to the remaining lot.

Gerstein (12) performed an interesting series of experiments using rupture discs. In his investigation, rupture discs, made of material that would burst at 245 psia in static tests, were placed at the end of a long shock tube. 
According to the results that were obtained, the discs ruptured although their theoretical: bursting pressure was well above the theoretical steady-state detonation pressure. Since the discs were made of thin metal, Gerstein postulated that the discs may have been set into vibration; thus, failure may have been partially from vibrational fatigue.

A disc designed for a static bursting pressure of 465 psia was also inserted at the end of the same tube. This disc was ruptured at a theoretical bursting pressure of 160 psia. From these results Gerstein concluded that rupture discs may fail at a lower dynamic load than under static loading.

In one of the earliest investigations of gaseous detonation by Campbell (4), the ratio between the unreflected detonation wave pressure and the initial gas pressure was studied using rupture discs. The value of the reflected wave pressure needed to rupture these discs was postulated to be equal to twice the unreflected wave pressure. Therefore, by determining the ultimate siress at which the disc would rupture statically, the unreflected wave pressure could be calculated. Campbell calibrated his discs under static air pressure and assumed that they would break at the same ultimate stress dynamically. Figure 2 gives the calibration in graphical form. 


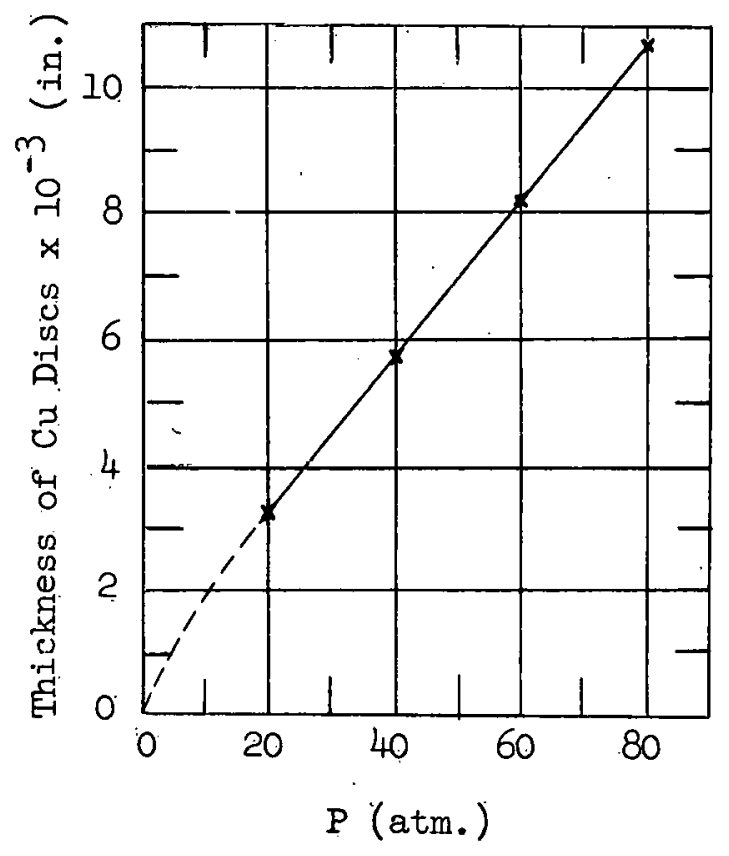

Figure 2

Calibration Curve - Thickness of Copper Discs vs Bursting Pressure

Campbell (4)

Table I gives the results Campbell obtained in his work.

Table I

Experimental Data Obtained by Campbell (4)

Thickness of Cu (in.)

Pressure (atm.)

(Jouget)

mixture sheared unsheared sheared unsheared mean calc.

\begin{tabular}{c|cccccc}
$2 \mathrm{H}_{2}+6 \mathrm{O}_{2}$ & 0.0045 & 0.0057 & 19 & 15 & 15 & - \\
$2 \mathrm{H}_{2}+\mathrm{O}_{2}$ & 0.0057 & 0.0063 & 21.8 & 19 & 20.4 & 21.1 \\
$7 . \mathrm{H}_{2}+\mathrm{O}_{2}$ & 0.0045 & 0.0057 & 19 & 15 & 19 & 16.1
\end{tabular}


Campbell mentioned in his article that the static pressure required for rupture depended to a slight extent on its rate of application. This would indicate that the dynamic ultimate stress may be different from the static ultimate stress.

Stewart (22) performed some bursting, tests upon aluminum foil rupture discs in order to prove their usefulness in industry. These tests were carried out in four different manners: (1) initial pressure atmospheric, pressure applied gradually; (2) initial pressure atmospheric, pressure applied suddenly (shock or better called impact loading); (3) initial vacuum, pressure applied gradually; and (4) initial vacuum, pressure applied suddenly. The test procedures are outlined in the article. Table II is a summary of all experimental data showing the bursting pressure of aluminum foil rupture discs as a function of foil diameter, thickness, temper, initial loading and rate of application of pressure.

\section{Table II}

Experimental Data Obtained by Stewart (22)

Tank Size Rupture Disc Bursting Pressure psig.

\begin{tabular}{|c|c|c|c|c|c|c|}
\hline $\begin{array}{l}\text { Tank Size } \\
\text { Nominal-In. }\end{array}$ & $\begin{array}{l}\text { Rupture Disc } \\
\text { Thickness-In. }\end{array}$ & Temper & $\begin{array}{l}\text { From } \\
1 \text { atm. }\end{array}$ & $\begin{array}{r}\text { From } \\
\text { Vacuum }\end{array}$ & $\begin{array}{l}\text { From } \\
\text { I atm. }\end{array}$ & $\begin{array}{l}\text { From } \\
\text { Vacuum }\end{array}$ \\
\hline \multirow[t]{6}{*}{2} & 0.001 & 0 & 4 & - & - & - \\
\hline & 0.001 & $\mathrm{H}-18$ & 13 & - & - & - \\
\hline & 0.002 & 0 & 18 & 18 & 19 & 19 \\
\hline & 0.003 & 0 & 43 & 44 & 41 & 42 \\
\hline & 0.003 & $H-18$ & 40 & 31 & 38 & 33 \\
\hline & 0.0045 & 0 & 60 & 62 & 58 & 56 \\
\hline
\end{tabular}


Table II (Con't.)

Bursting Pressure psig.

Tank Size Rupture Disc

\begin{tabular}{|c|c|c|c|}
\hline \multicolumn{2}{|c|}{ Gradual } & \multicolumn{2}{|c|}{ Impact Load } \\
\hline$\overline{\text { From }}$ & From & $\overline{\text { From }}$ & From \\
\hline 1 atm. & Vacuum & $1 \mathrm{~atm}$. & Vacuum \\
\hline 64 & 66 & 63 & 62 \\
\hline
\end{tabular}

4

Nominal-In.

2

$\frac{\text { Thickness-In. }}{0.005} \frac{\text { Tempe }}{0}$

64

66

63

62

0.001
0.001
0.002
0.003

$\mathrm{O}$
$\mathrm{H}-18$

0.003

0

2

0.0045

H-18

21

7

0.005

$$
0
$$

30

0

31

0.005

$\mathrm{H}-18$

48

0

69

0.008

0

83

0.010

H-18

80

0.001

0.001

0

0.002

H-18

0.003

0

0.003

0

H-18

0.0045

0

0.005

0

0.005

H-28

0.008

0

0.010

0

57

15

12

15

15

15

1. 'l'emper designation:

$0=$ Dead Soft

- 10

21

20

19

18

22

23

35

20

20

30

47

28

28

47

57

47

57

43

53

2. - indicates no test possible.

H.--1.8 = Full Hard 


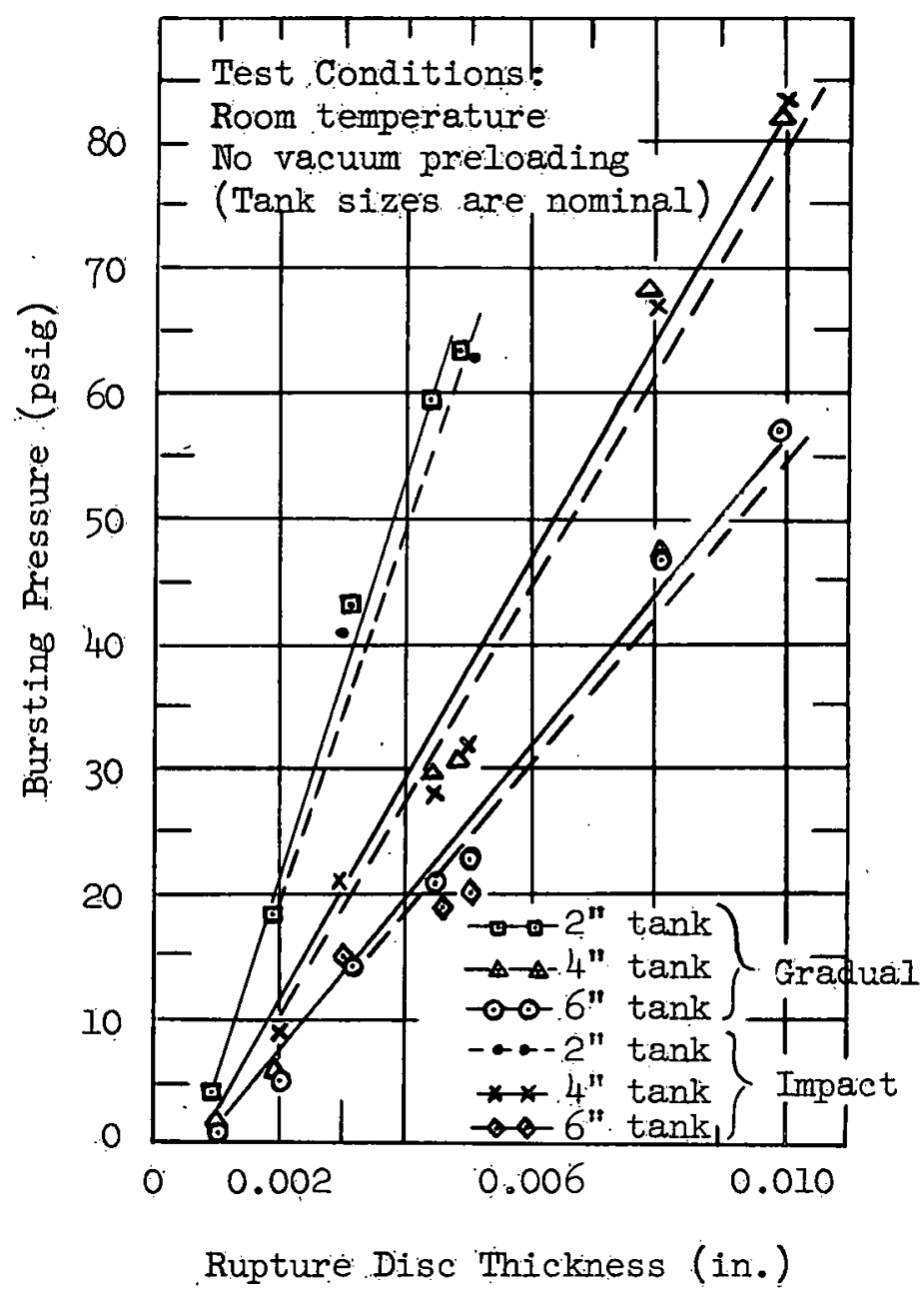

Figure 3

Bursting Pressure vs Disc

Thickness for 2S-O Aluminum

Stewart (22)

Figure 3 is a plot of the bursting pressure of aluminum 2S-O discis (inttially at atmosphëric pressure) as a function of disc diameter and thickness. The figure shows a linear relationship between bursting pressure and disc thickness for each of the three 
diameters tësted. This figure also shows that at a constant disc thickness the static pressure or impact bursting pressure required to rupture the disc was inversely proportional to the disc diameter.

Stewart determined that vacuum preloading had essentially no effect on the bursting pressure of the 2S-0 discs that were either loaded gradually or subjected to impact loading. However, with yacuum preloading the bursting pressure was greater for gradual loading than for impact loading. From these results stewart concluded that the ultimate yield stress of the material is essentially the same under both types of loading (gradual and impact). c. Work Hardening

The study of the strength of materiais must not only include the determination of the ultimate yield stress but also the effect of work-hardening upon the ultimate yield stress. In industry the replacement cost on equipment may be very high. Therefore, any method or idea that could eliminate the replacement of equipment would be very valuable:

If a piece of equipment was subjected to a detonation, the question would arise whether that piece of equipment must be replaced or if it still can be kept in service. The equipment may still be used if the dynamic ultimate yield stress does not decrease because of the detonation. If the ultimate stress does decrease, then the equipment must be replaced. The study of work-hardening can supply the answe to this important question. 
To study the effect of work-hardening the mechanism and theory of materials undergoing strain-hardening must first be known.

Slip (17) in a crystalline material may be postulated to progress in either of two ways:

a). One whole plane of atoms moves simultaneously over another plane.

b) Slip begins at one point and propagates itself over the slip plane.

The theory set forth in statement (b) gives better values of strength than statement (a); however, the theory of dislocations must be used in association with statement (b).

An important mechanism of plastic flow in many metals as described by Barrett (2) is deformation by twinning which consists of shearing movements of the atomic planes over one another. The shearing appears to be homogeneous under the microscope as there is a uniform tilting of the surface in the twinned region; however, in many crystals it is not true homogeneous shear in the sense that every atom shifts a distance $\alpha$ to its distance from the twinning plane. Iron and alloyed ferrites are twinned by impact at room temperature and by slower deformation at lower temperatures to form the narrow lamellae known as Neumann bands as shown in Figure 4. These bands have small but readily visible widths, unlike slip planes, and appear prominently after polishing and etching. Deformation and work- 
hardening occur when it is easier for the crystals to remain in their new position instead of returning to their original position.

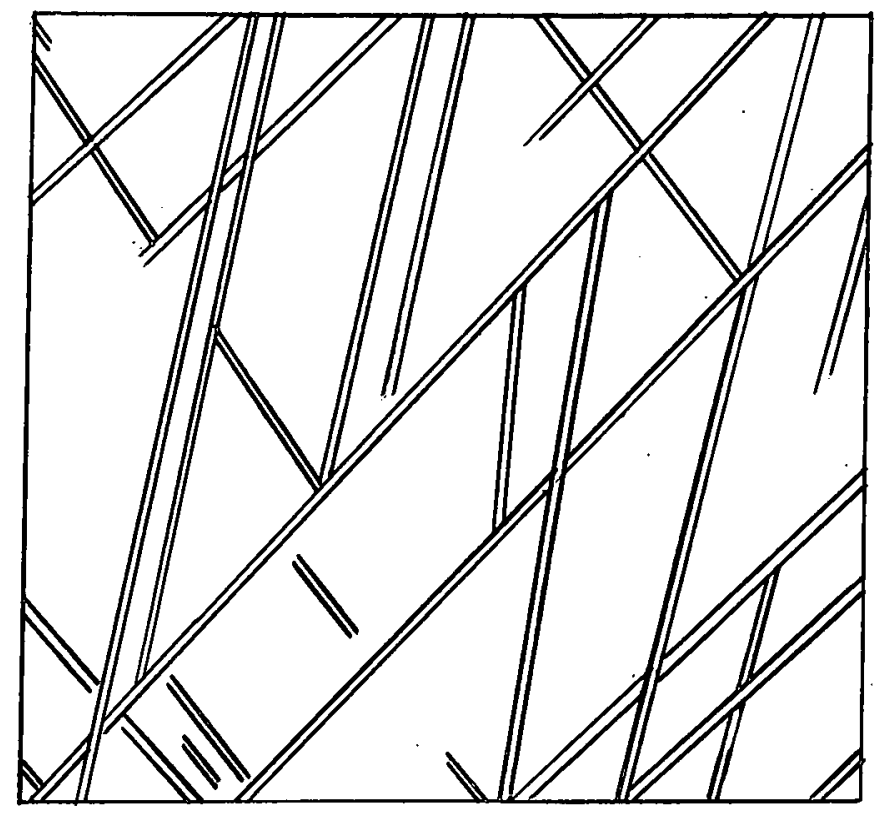

Figure 4

Neumann Bands Formed by Impact in

Iron and Alloyed Ferrites; Barrett (2)

Barrett stated that the shear stress necessary to cause

slip is always increased by prior cold work. The shear stress that

is essential to continue slip increases with the percent (\%) of shear strain. The rate of strain-hardening also depends on the structure of the metal. This is illustrated in Figure 5 . 


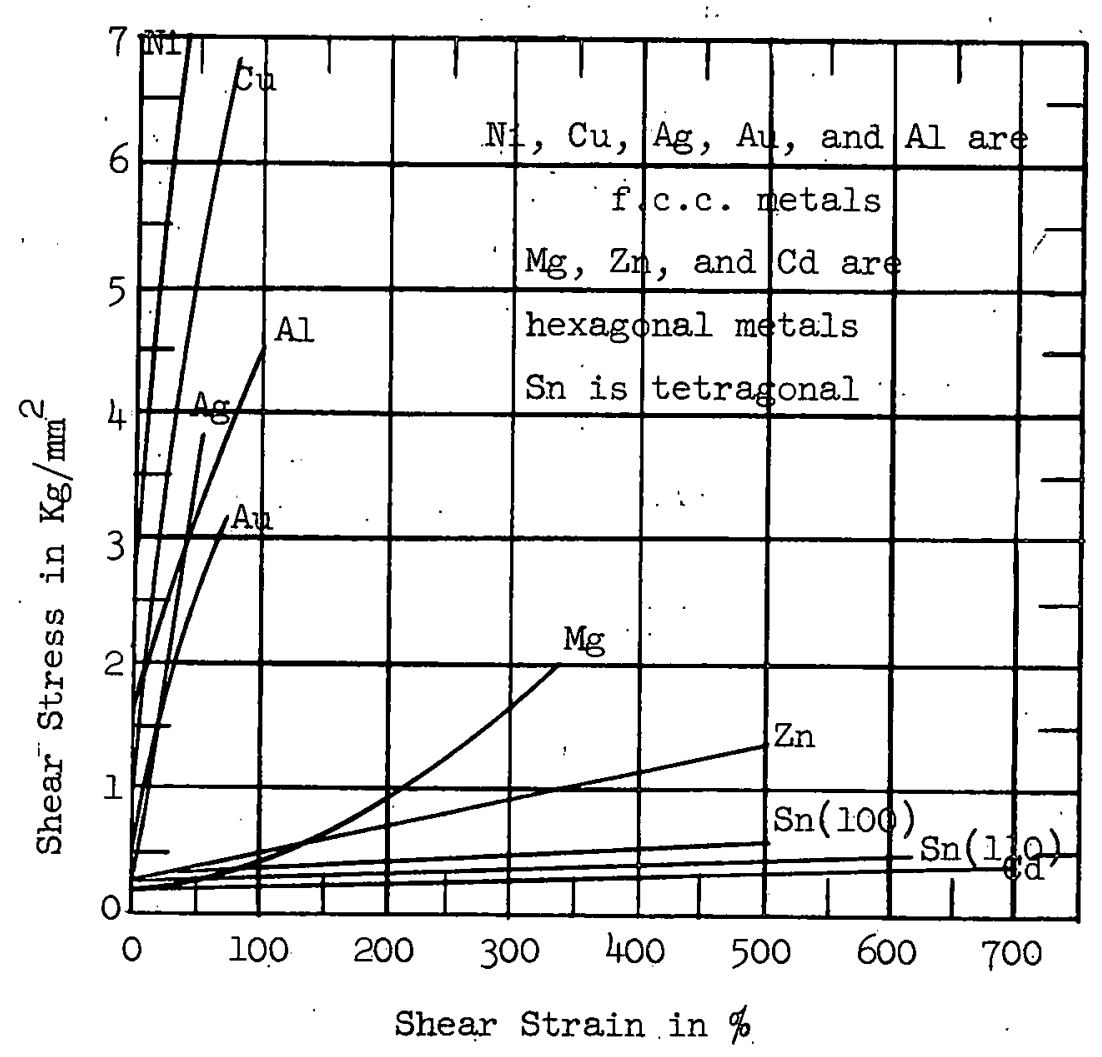

Figure 5

Shear Stress vs Shear Strain

for Various Metals; Barrett (2)

Aluminum hardens along a parabolic curve. The entire strain-hardening curve, including the initial critical stress, is a function of the rate of deformation. The shape of the curve can be dependent, for example, on whether the stress or the strain is increased uniformly with time. This is shown in Figure 6. 


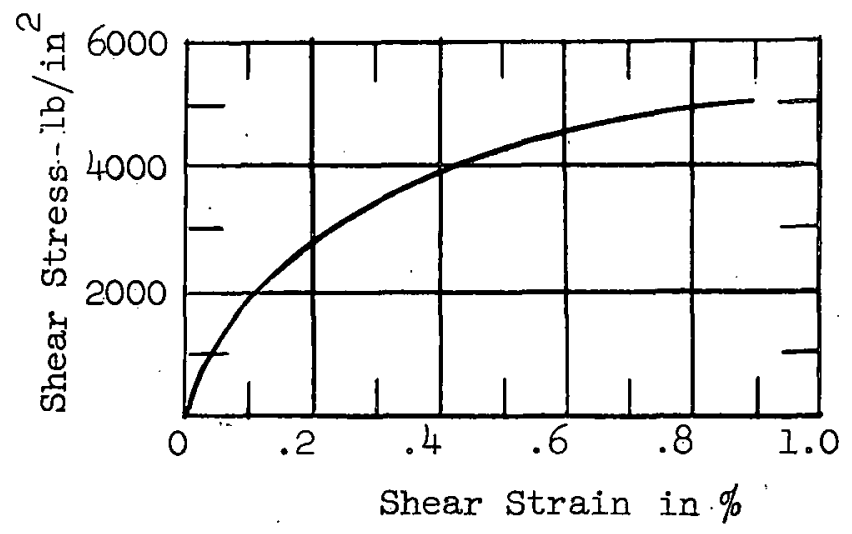

Figure 6

Strain-Hardening in Aluminum;

Barrett (2)

The mechanical characteristics, such as the stress-strain curve, of a material are strongly influenced by any previous work the specimen has undergone. As a specimen is strained, the ability of the metal to withstand further stressing of the same type is increased while the strength of the material to stresses of the opposite type is decreased. This is called the Bauschinger effect and can be ascribed to the state of stress existing within the metal after the first deformation. If some grains of the aggregate have an orientation such that they have a higher yield strength to an applied tensile load while others have a low yield strength, then when the load is removed, the latter will be brought into a compressive strain by the tensile stresses in the former and the final state is an 
equilibrium between compressive and tensile stresses in many small regions. Consider now the state of stresses upon reapplication of the tensile load to the grains that were originally the weak ones and that are now the compressive ones. The compressive grains must be first reduced to zero stress from their elastically compressed state and then raised to their yield strength in tension before flow can begin. The material has been consequently work-hardened for tensile stresses. A more fundamental point of view which accounts for the effects in both single crystals and polycrystalline speci-.. mens is that the effects are due to stresses that surround the individual slip bands where relative displacement of the two sides of the slip bands has occurred.

There have been various other theories stated on the reason for the work-hardening effect in materials (8). The oldest theory was developed by Bielby and Rosenheim. Rosenheim originally stated that when plastic deformation takes place, a minute amount of hard amorphous metal is formed between slip planes which is assumed to interfere effectively with the smooth gliding of the slip planes. Resistance to slip is determined by the amount of amorphous metal formed which in turn is dependent upon the degree of work-hardening. The increase of resistance to slip was assumed by Rosenheim to contribute to the hardness and strength of the material; however, this phenomena cannot be seen by X-Ray investigators. 
A second theory developed by Jeffries and Arches also involves the presence of matter between slip planes. In this case a certain amount of fragmentation or disruption of atomic layers occurs and metals are plastically deformed. The fragments from the disruption of the atomic layers form small crystals differently orientated with respect to metal adjacent to them. This will also obstruct smooth gliding of planes, and therefore increase the strength of the material. The strength of a metal is raised if slip is retarded or prevented. The presence of a substance between the slip planes offers obstruction to smooth gliding and tends to retard slip. Lattice deformation would also hinder slip because of distortion of the crystal structure.

Fragmentation accompanying excessive cold work simulates structure of a fine-grain metal which introduces added grain boundaries, that act to obstruct the progress of slip to adjacent grains:

Strain-hardening appears to be very small when slip is confined to one system but is greater when two systems operate simultaneously and is still greater when three or more are operating. Cottrell (in a private communication to Barrett (2)) suggested that, by analogy with fluid flow, the single slip condition be called "laminar flow" and the other (rapid strain-hardening) conditions "turbulent flow". Although much importance had been. attached to subdivision of crystals into deformation bands during plastic flow, it now appears that these are relatively unimportant. 
in causing strain-hardening; that is, deformation bands may be present when hardening is slight and may be absent when hardening is rapid ..- at least in f.c.c. single crystals. Cottrell also pointed out that the stress field from the boundaries of a deformation band must not extend far away from the boundary, hence it cannot be expected to harden the major portion of the crystal.

Matt (17) suggested a different theory of strain-hardening which is called the dislocation theory. A dislocation is a line discontinuity extending across a crystal or crystalline grain and lying in a slip plane. Let the plane of this paper be the slip plane as shown in Figure 7; all the material above the area $A$ has been displaced one atomic distance, $x$, in the slip direction while the material above $B$ has not slipped. Line $C D$ is then called the dislocation. For a few atomic distances to either side in the region shown shaded, the slip distance is between $x$ and zero. Matt; assumed that for each dislocation there exists a minimum stress $\sigma_{i}$ ' which, if applied to the crystal, will set the dislocation into motion.

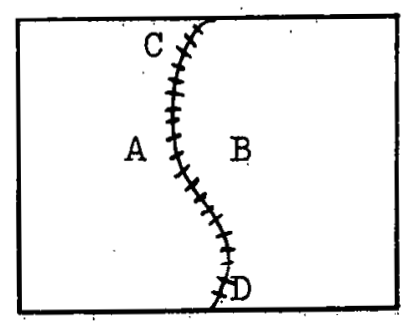

\section{Figure 7}

A Dislocation in a Crystal; Matt (it) 
The process of work-hardening must thus be understood in the following manner. When the first deviations from proportionality between stress $(\sigma)$ and strain $(\epsilon)$ occur, there is a slip band formed for which $\sigma_{i}$ is particularly small. The initial hardening is then due to the exhaustion of easily moved dislocations and not necessarily to the creation of internal stresses. After some rather small plastic strain $(\cong 1 \%)$, all the easily moved dislocations will be used up and further slip will have its origin in new dislocations in the slip bands that have been previously formed. The value of $\sigma_{i}$ for these dislocattions will increase; however the magnitude of the increase will depend on the density of dislocations in the hardened material around them. This is physical hardening. The greater $\sigma_{i}$ becomes, the greater is the strength of the material. Zwikker (25), in addition, stated that the presence of internal stresses due to local impurities, precipitates; or crosswise dislocations will increase the hardening effect. Any moving dislocation may overcome many of these obstacles but will stop before a particularly severe one. Shear, therefore, reaches a saturation value which can only be raised with ever increasing difficulty by raising the value of the external shear stress.

In the transformation from single cyrstals to the study of polycrystalline metals many new complicating factors enter into the discussion. The most important of these factors are the grain 
boundaries, the constraints imposed on the flow of a grain by the flow of the aggregate, and by the various orientated neighboring grains. The homogeneous strain of the single crystal is replaced by a heterogeneous strain that varies from grain and from point to point within a grain.

Chalmers (5) conducted an experiment with tensile specimens composed of two crystals of tin in which the boundary between the pair of crystals extended longitudinally throughout the specimen. The results obtained by Chalmers showed that the critical stress depends upon the difference in orientation between the two crystals; being a minimum when the lattice in the two crystals are similarly orientated and a maximum when the orientation differs the most. This indicates that when slip planes in two adjacent grains are not parallel it is difficult for the block movement in one grain to cross the boundary into the next grain. There seems no need to assume that there exists an amorphous cement along the boundaries which imparts additional strength to the whole.

Polycrystalline metal generally offers more resistance to deformation than single crystals. As grain size is reduced, resistance to deformation increases in iron and aluminum. The yield strength in some alloys can be taken as proportional to $(I / D)^{1 / 2}$ where $D$ is the average grain diameter.

Gensamer $(10,11)$ and his collaborators studied the 
quantitative relation between the fineness of the microstructures in steel and the tensile properties. Gensamer plotted the resistance to deformation at a constant value of strain against a measure of the fineness which is reproduced in Figure 8 . The measure of fineness used was the logarithm of the mean straight path through the continuous phase (ferrite) from one hard cementite particle or lamella to another. From Figure 8 it can be seen that the stress is inversely proportional to the log mean ferrite path.

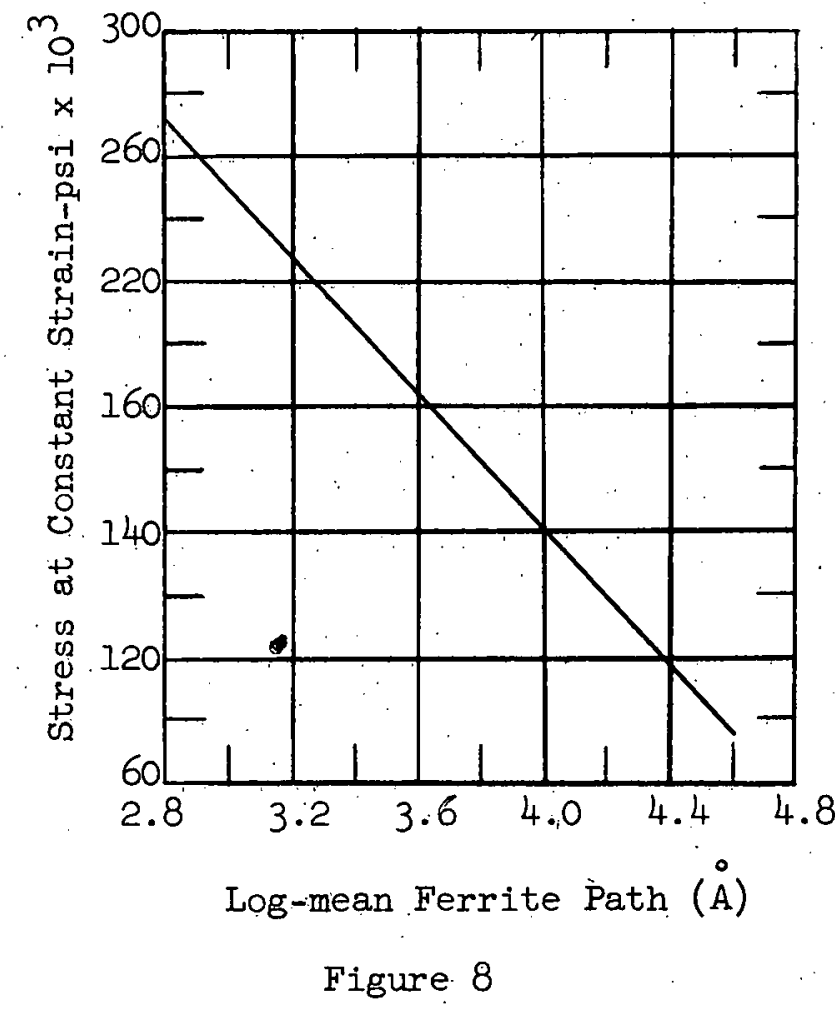

Relationship Between Resistance to Slip and Fineness of the Microstructure in Steel; Gensamer (10, 11) 
Coonan (8) summarized the effects of work-hardening by stating that cold deformation increases hardness, tensile strength, and yield point of a metal. The magnitude of these changes is dependent upon the nature and the amount of deformation.

Tabor (23) said that under dynamic loading work-hardening will occur during the time when the shock wave hits the disc.

Barrett (2) mentioned that there is a slight effect of strain rate upon the resistance to deformation. The increase in resistance to slip is proportional to the logarithm of the rate of straining and there is a greater increase shown in the soft metals... than in the hard metals.

Barrett also stated that the temperature at which the metal is cold-worked affected the amount of work-hardening. Figures 9 and 10 show both of these effects. The amount of strain-hardening decreased markedly as the temperature is raised. Figure 9 is for Mg (2l). The dash curves $\left(100^{\circ} \mathrm{S}\right.$ and $\left.250^{\circ} \mathrm{S}\right)$ mark a rate of test about a hundred times faster as compared to the remaining curves. Barrett noted that while the rate is not an important factor at $100^{\circ} \mathrm{C}$, the rate exerted a profound effect at $250^{\circ} \mathrm{C}$. Figure 10 is for aluminum (3).

Sachs (20) postulated a theory on the work-hardening of some stainless steels. According to Sachs' theory, alloys $18 / 8$ or 


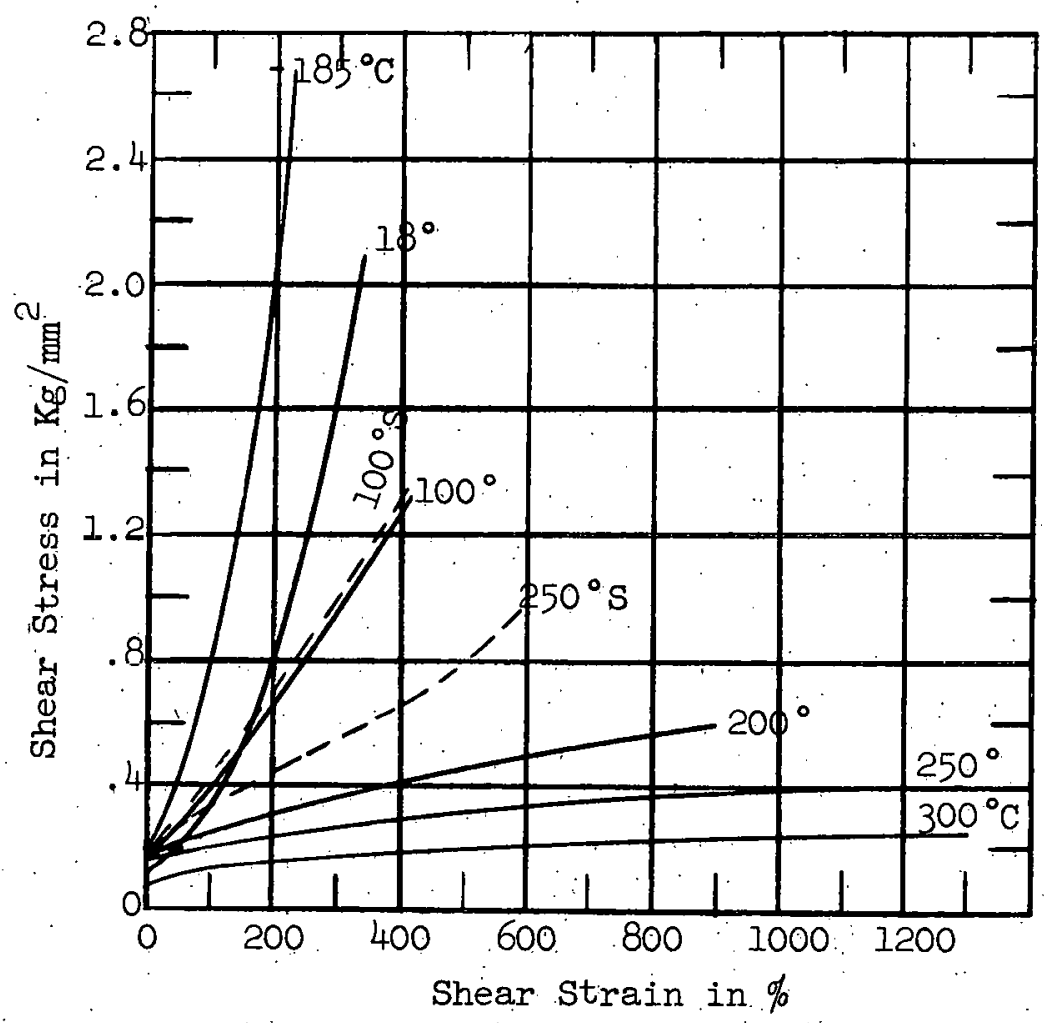

Figure 9

Strain-hardening in Mg Crystals at different Temp.; Schmid (2l) 


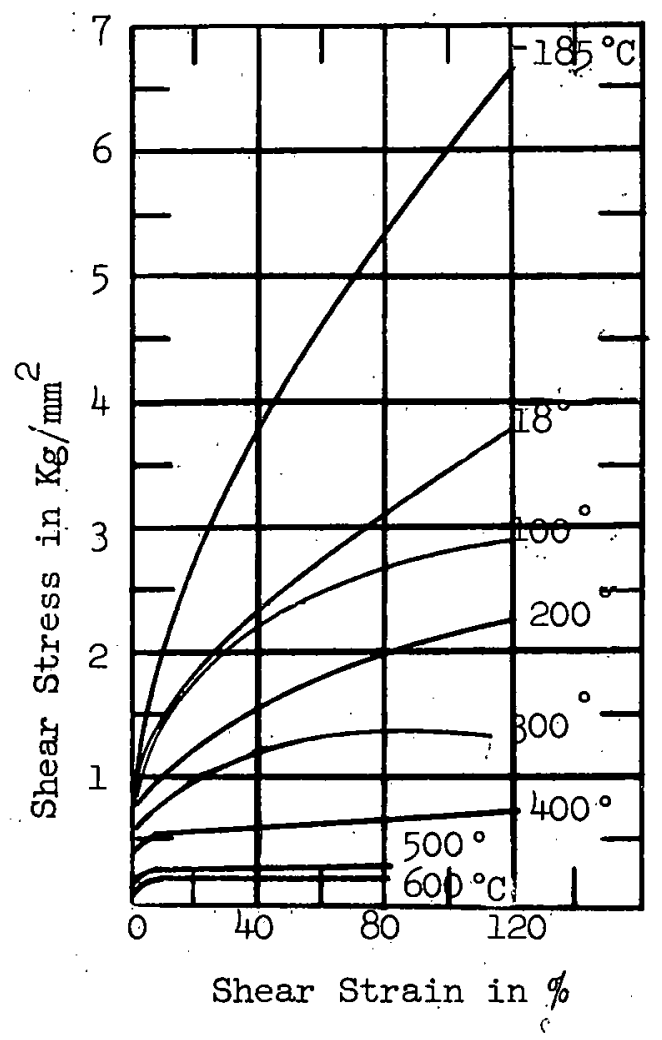

Figure 10

Strain-hardening in Aluminum Crystals; Boas (3)

austenitic stainless steel change. on cold-working to the ferritic condition of the iron-solid solution. This change explained the extraordinary strength of the strain-hardening capacity of $17 / 7$ and the gradual decrease in work-hardening with increasing nickel content.' An alloy with a sufficiently high nickel content does not transform at all. The difference between the curves in Figure Il represents the effect of the transformation which is superimposed upon the normal strain-hardening. The magnitude depended on 
the rate at which the transformation proceeded with increasing reduction of area; however, the rate in turn depended upon composition and conditions of cold-working.

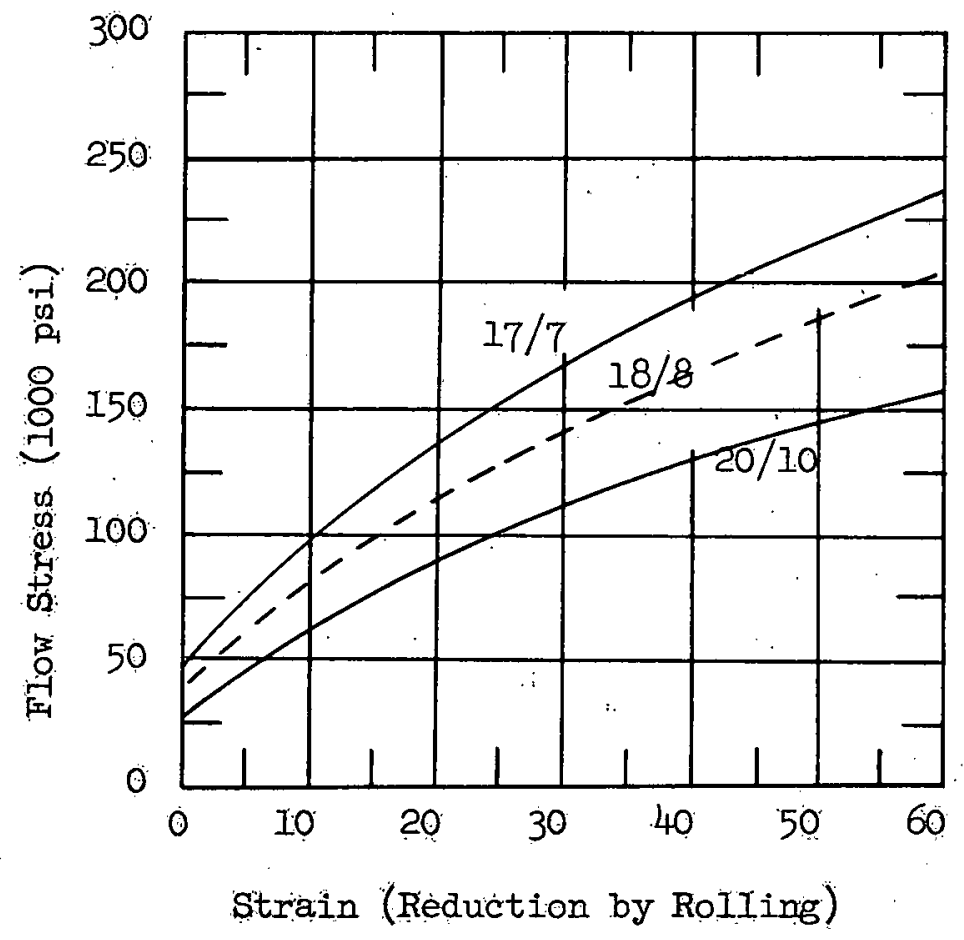

Figure 11

Stress vs Strain for Various Stainless Steels as a Function of ivickel Content

Sachs (20)

D. Scope of Investigation

A material will fracture when a stress equal to the ultimate yield stress is applied to it. This has been determined under static loading for many structural materials. However, in today's industry there is another question that must be answered. Because of the nature of many processes, the value of the dynamic 
ultimate yield stress must be known either directly or as a function of the static ultimate stress.

A few men have performed experiments relating to this question. Gerstein postulated that the ratio of dynamic to static ultimate stress is less than one while others have surmised that the ratio is essentially equal to one. However, there are enough scattered facts available to believe that the ratio may be greater than one.

If a material is subjected to an impact stress which is below the upper dynamic yield stress, the material would not rupture but would deform. This deformation would increase the hardness of the material. Some investigators believe that the upper dynamic yield stress will increase to a value greater than for an undeformed. specimen. As the hardness increases the upper dynamic yield stress will increase until a limit is reached. This limit would occur when the property of fatigue overcomes the effect of work-hardening. Then the material will theoretically rupture at a lower applied stress. To completely predict the behavior of any material under stress the stress-strain diagram must be ascertained; therefore the ultimate stress, the elastic limit, and the yield point must be known. As of this moment, there is insufficient information available on the dynamic stress-strain diagram for little is known of the dynamic properties of materials. 
This work is then concerned with the determination of the dynamic ultimate stress of materials, particularly stainless steel-type 304. The determination is based on the comparison of the static and dynamic ultimate stress, which will be one point on the dynamic stress-strain curve. Many investigators have postulated that the dynamic ultimate stress will increase if the material is dynamically work-hardened. As a result of this, the effect of dynamic work-hardening on the dynamic ultimate stress of a material is also investigated. 


\section{Apparatus}

The apparatus for the fracturing and testing of the rupture disc included the following components:
A. Detonation tube
B. Rupture disc assembly
C. Spark plug
D. Filling system

The detonation tube was a shock tube six (6) feet long and was constructed of seamless steel tubing. The tube had an outside diameter of 1.125 inches and an inside diameter of 0.687 inches. One end of the tube was threaded to receive the rupture disc assembly and the other end was internally threaded for the spark plug as shown in Figure 12.

From theoretical calculations it was shown that the shock tube will not fracture in service. The formula useful in determining the bursting pressure of the tube was as follows:

$$
P=2 f(t / D)
$$

where

$$
\begin{aligned}
& P=\text { ultimate bursting pressure in psi } \\
& f=\text { fiber stress in psi } \\
& t=\text { thickness of tube in inches } \\
& D=\text { diameter of tube in inches. } \\
& \text { For the tube in question, } f=60,000 \mathrm{psi}, t=0.219 \text { inches }
\end{aligned}
$$

and $D=1.125$ inches. The theoretical bursting pressure would there- 
fore be $23,360 \mathrm{psi}$. This is equal to the internal tube pressure necessary to cause rupture of the shock tube. Since the maximum internal pressure that is expected to be developed during the experimentation is only $12,000 \mathrm{psi}$, it was concluded that the tube would withstand all possible detonations.

The shock tube was filled with a stoichiometric detonable gaseous mixture of hydrogen and oxygen through a section of superpressure tubing which was welded to the detonation tube.

The rupture disc assembly which was used was purchased from the American Instrument Company. It was modified to specifications as shown in Figure 12. The assembly was made of stainless steel -304 .

The spark plug that was used to set off the detonations. was specially designed and built for this system since a standard. spark plug would break under the force of a detonation. The spark plug consisted of a nichrome wire which acts as an electrode with a teflon insulator. The spark gag was formed between the nichrome wire and the inside wall of the shock tube. The teflon proved to be an effective seal for the spark plug. A diagramatic sketch of the apparatus is presented in Figure 12 .

The filling system was elaborately designed to insure safety during all necessary operations. All lines exposed to high 
pressures were constructed of $1 / 4$ inch O.D. - 3/32" I.D. superpressure stainless steel 304 tubing. which has an approximate yield pressure at room temperature of $25,000 \mathrm{psi}$. Low pressure lines were constructed of aluminum.

Stainless steel high pressure needle valves were used to throttle the gaseous mixture and as positive shut-offs. These valves used had a maximum safe working pressure of 30,000 psi. All the high pressure equipment was purchased from the American Instrument Company.

Figure 13 is a diagramatic representation of the entire system.

The rupture discs to be used in this investigation were manufactured by the American Instrument Company. All discs to be used were calibrated statically for rupture by the supplier. Table III is the complete list of discs used giving the rating of each set of discs and their material of construction.

\section{Table III}

Static Rating of Rupture Discs

Carbon Steel Nickel Phosphor Bronze Stainless Steel-304

$903 \mathrm{psi}$

340 psi. $\quad 1540$ psi

$1390 \mathrm{psi} 5280 \mathrm{psi}$

$2850 \mathrm{psi}$

$1250 \mathrm{psi}$

2070 psi

$1880 \mathrm{psi} \quad 6240 \mathrm{psi}$

2620 psi $7240 \mathrm{psi}$

3450 psi 9100 psi 
The complete facilities of the Detonation Research Laboratory of the Syracuse University Research Institute was also at the disposal of the investigator. 


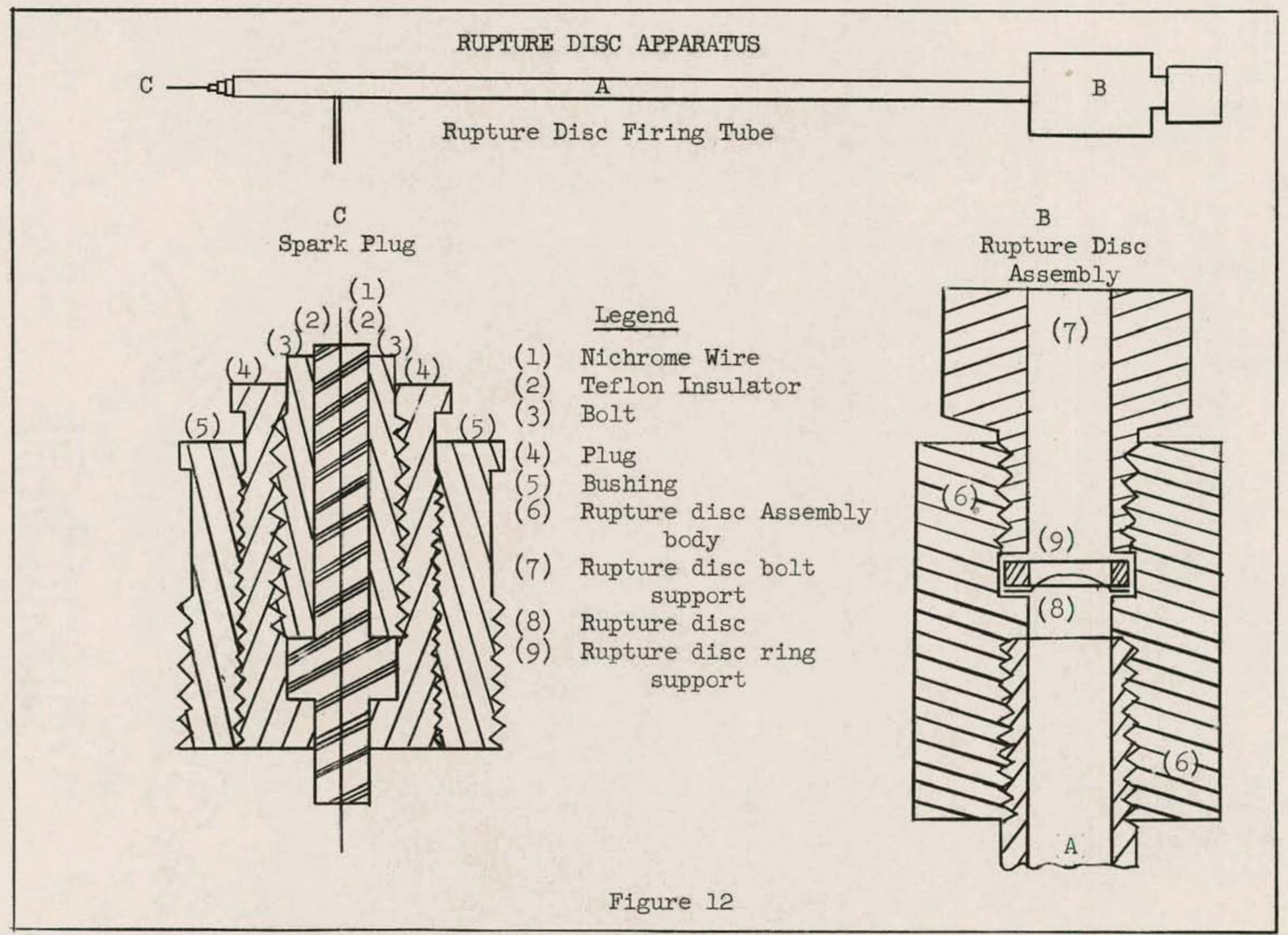




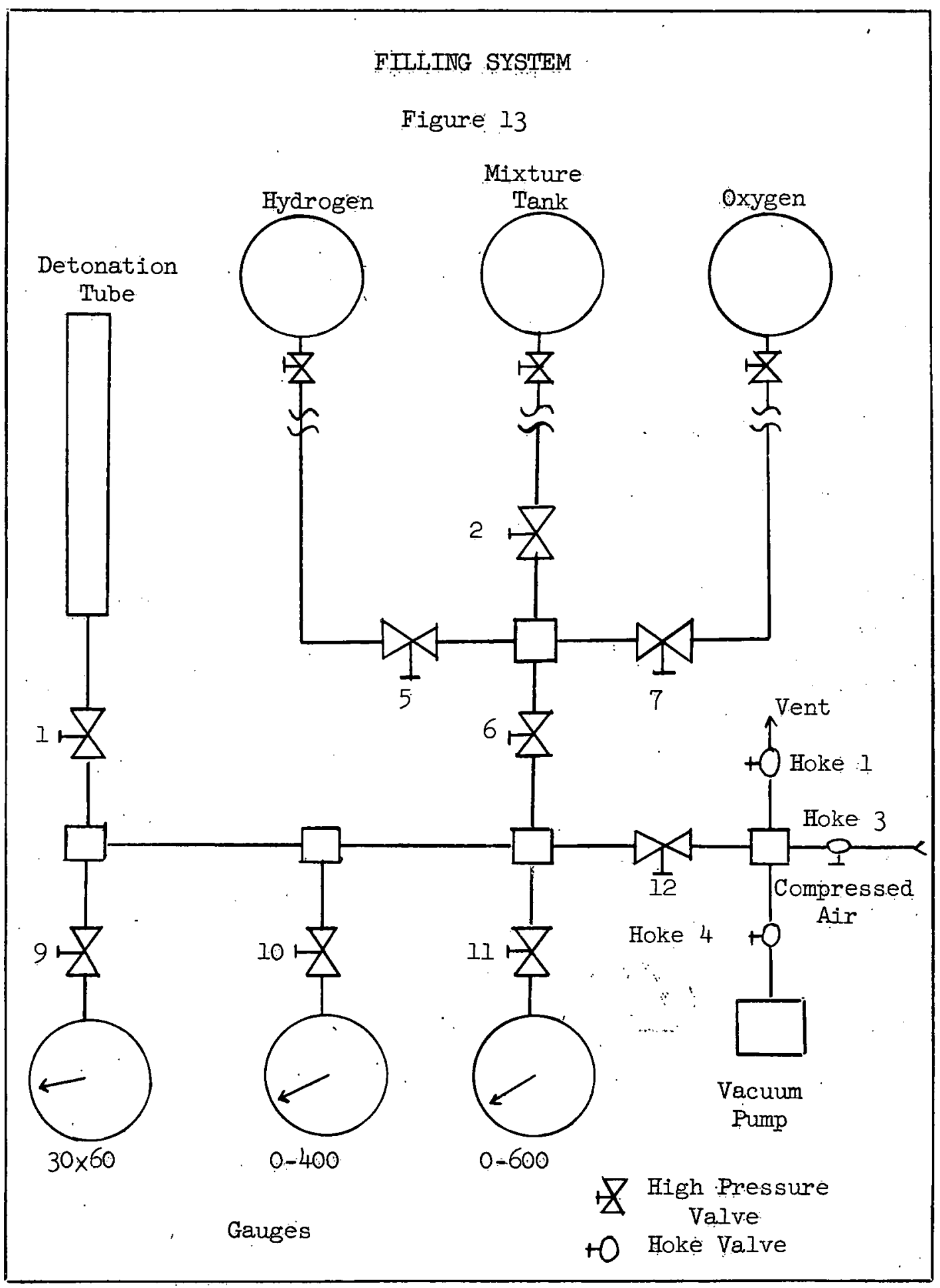




\section{Experimental Procedure}

The experiments conducted included the determination of the dynamic ultimate stress of a material and the effect of workhardening upon the dynamic ultimate stress. The equipment used was described in the section for apparatus and only rupture discs were used. All tests were conducted at room temperature.

The dynamic ultimate stress was determined as the pressure required to fracture each rupture disc. This data was collected in the following manner:

At the outset the shock tube was filled with a stoichiometric mixture of $\mathrm{H}_{2}$ and $\mathrm{O}_{2}$ to an initial pressure which would yield a reflected detonation pressure ten percent (10\%) above the static. rating of the disc. (See Operational Procedure for shock tube at end of this section:) The mixture was then detonated.

At this point there were two possible procedures that could be followed. If the disc did not fracture, it was replaced by an undeformed disc and the initial pressure adjusted to a slightly higher value. This procedure was repeated until an undeformed rupture disc fractured. This determination bracketed the dynamic ultimate stress to a small interval of pressures. The initial pressure was then successively lowered to the point where the discs just fractured; thus clearly establishing the dynamic ultimate stress. 
The other alternative was that the disc fractured at a detonation pressure ten percent (10\%) greater than the static rating. If this was the case, the fractured disc was replaced with an undeformed disc and the initial pressure adjusted such that the detonation pressure developed would be lower. The initial pressure was then successively lowered until a new disc would not fracture as a result of the detonation. Then the initial pressure was increased until the resultant detonation fractured the undeformed disc.

The determination of the effect of work-hardening upon the ultimate stress was determined from the fracturing stress of deformed discs. The method employed in this part of the study similar to the determination of the ultimate stress for an undeformed specimen. The main difference between the two methods was the history of the disc prior to fracture. The initial dynamic stress applied to the disc was equal to the stress produced by a detonation wave equal to $95 \%$, $90 \%$ and $80 \%$ of the ultimate stress. After the discs had: been subjected to an initial stress, the ultimate stress of a deformed disc was determined in an analogous manner to the determination of the ultimate stress of an undeformed specimen.

The mixture used for all detonations was withdrawn from a tank buried in the ground. This tank was filled with a stoichiometric mixture of $\mathrm{H}_{2}$ and $\mathrm{O}_{2}$ at an initial total pressure of 300 psia (see 
directions for filling mixture tank at the end of this section), and sufficient time was allowed for mixing. 


\section{OPERATIONAL PROCEDURE}

1. All valves closed

2. All electrical circuits open

3. Replace: used rupture disc with new one

4. Turn on vacuum pump

5. Open hoke valve 4 (vacuum pump)

6. Open val.ves 12,9 and 1

7. After desired vacuum, elose valve 12 , hoke 4 and valve 9

8. Turn off vacuum pump

9. Open valve 2

10. Use valve $9(30 \times 60)$, valive $11(0-600)$ or valve $10(0-400)$ for desired initial pressure range.

11. Use valve 6 for filling with mixture to desired initial pressure

12. Close valve 2

13. After equilibrium, record initial pressure

14. Close valve $I$ and valve 9 , or 11 , or 10

15. Turn on vacuum pump, hoke valve 4, valves 12 and 9

16. After system is evacuated; close valves 12; 9 and hoke 4

17. Close vacuum pump

18. Close master switch

19. Close secondary switch $I$

20. Fire

21. After firing, remove rupture disc

22. Turn on air compresser and open hoke valve 3 , valves 12 and 1

23. After letting air flow through tube for a couple of minutes, repeat operational procedure $(1-23)$ for next run.

$\mathrm{All}$ valve numbers refer to valves shown in Figure 13 in the section on apparatus. 


\section{DIRECTIONS FOR FLLIING MTXTURE TANK}

Use $0-400$ gauge to add $\mathrm{H}_{2}$

Use $0-600$ gauge to add $\mathrm{O}_{2}$

1. Evacuate system

2. Close all valves

3. Shut down all instruments and pumps (Open all circuitș)

4. Open outside valves to $\mathrm{H}_{2}$ and mixture tank

5. Open valves $: 2,6$ and 9

6. Crack valve 7 until pressure is greater than atm. Then close valve 7 .

7. Close valve 9

8. Open valve 10

9. Crack valve 7 until $\mathrm{H}_{2}$ pressure $=187 \mathrm{psig}$. Close valve 7 .

10. Close valve 2

11. Close outside valve to $\mathrm{H}_{2}$ tank

12. Open hoke valve 1

13. Open valves 12 and 7

14. Close hoke valve 1 and valve 10 after system has been reduced to atm. pressure

15. Turn on vacuum pump and open hoke valve 4

16. Open valve 9

17. After system has been evacuated, close valves 7,12 and hoke 4

18. Close vacuum pump

19. Open outside valve to $0_{2}$ tank

20. Crack valve 5 until vacuum gauge shows positive pressure, then close valves 5 and 9

21. Open valve 11

22. Crack valve 5 until $0_{2}$ pressure is greater than 190 psig., then open valve 2 . When mixture pressure $=285.7$ psig., close valve 5 
DIRECTIONS FOR FILLING MTXTURE TAINK (CON'T)

23. Close valve 2 , outside valves to $\mathrm{O}_{2}$ and mixture tank

.24. Open hoke valve 1 and valves 12,5 and 2 until system pressure $=$ 0 gauge

25. Close hoke valve 1 and valve 11

26. Turn on vacuum pump and open hoke valve 4

27. Open valve 9

28. After system has been evacuated, close valves $12,2,5,6,9$ and hoke valve 4

29. Close vacuum pump

All valve numbers refer to valves shown in Figure 13 in the section. on apparatus. 


\section{Results}

Tables IV, V, and VI give in tabular form the results obtained in this study. The values of the dynamic ultimate stress are listed in Table $I V$. Table $V$ lists the values of the dynamic ultimate stress after a single work-hardening effect, while Table VI lists the dynamic ultimate yield stress after a double workhardening effect.

A complete tabulation of the experimental data is presented in Appendix A. Figures 14 and 15 give in graphical form the data obtained for stainless steel-type 304, nickel, phosphor bronze, and cold-rolled steel. The results of the work-hardening effect upon the dynamic ultimate yield stress of stainless steeltype 304 are plotted in Figure 16.

A complete interpretation of all results may be found by referring to the Discussion of Results. 


\section{TABIE IV}

Dynamic Ultimate Stress versus Static Ultimate:Stress

Disc Rating psi

1390

$1880^{\circ}$

2620

3450

5280

6240

7240

9100

340

1250

1540

2070

903

2850
Dynamic Ultimate

Stress-psia

Material

SS 304

SS 304

SS 304

SS $\cdot 304$

SS 304

SS 304

SS. 304

SS. 304

N

N

P.B.

P. B。

CRS

CRS
1770

2510

3390

4140

7000

7950

8840

11650

630

2140

2770

3670

1300

4460
Dynamic Ultimate Stress Rupture Disc Rating

1.27

1.34

1.29

1.20

1.33

1.27

1.22

1.28

1.85

1.71

1.80

1.77

1.43

1.56 
TABLE .V

Simple Work-hardening Effect

\begin{tabular}{|c|c|c|c|c|c|c|}
\hline $\begin{array}{l}\frac{\mathrm{A}}{\text { isc } \text { Rating }} \\
\text { psi }\end{array}$ & Material & $\begin{array}{c}\mathrm{C} \\
\begin{array}{c}\text { Dynamic Ultimate } \\
\text { Stress-psia }\end{array} \\
\end{array}$ & $\begin{array}{c}\stackrel{D}{\text { Initial }} \\
\text { Loading-psia } \\
\end{array}$ & $\begin{array}{l}\text { Dynamic UTtimate } \\
\text { Stress After. Work- } \\
\text { Hardening - psia }\end{array}$ & $\frac{F}{\left[\frac{E}{A}\right]}$ & $\frac{G}{\left[\frac{E}{C}\right]}$ \\
\hline 1390 & SS 304 & 1770 & 34.6 & 1950 & 1.40 & 1.10 \\
\hline 1390 & SS 304 & 1770 & 36.1 & 1910 & 1.37 & 1.08 \\
\hline 1880 & SS 304 & 2510 & 49.0 & 2840 & 1.51 & 1.13 \\
\hline 1880 & SS 304 & 2510 & 52.0 & 2880 & 1.53 & 1.15 \\
\hline 2620 & SS 304 & 3390 & 60.0 & 4070 & 1.55 & 1.20 \\
\hline 2620 & SS 304 & 3390 & 69.0 & 4300 & 1.64 & 1.27 \\
\hline 1540 & P.B. & 277.0 & 54.0 & 2770 & 1.80 & 1.00 \\
\hline 340 & $\mathbb{N}$ & 630 & 12.1 & 840 & 2.47 & 1.33 \\
\hline 903 & CRS & 1300 & 24.0 & 1810 & 2.00 & 39 \\
\hline
\end{tabular}

TABLE VI

00

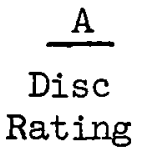

B

$\underline{\mathrm{C}}$

D

Double Work-hardening Effect

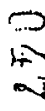

Dynamic Dynamic Ultimate

Stress After Simple

$\frac{E}{1}$

Initial Secondary

Untimate

Work-hardening-psia

Loading Loading

psi Material

Stress-psia

Work-hardening-psia

psia psia

4190
4190

69

72
F

\section{$\underline{G}$}

Dynamic Ultimate Stress After Double Work-hardening-psia

$\begin{array}{ll}80 & 4600 \\ 80 & 4460\end{array}$

H I J

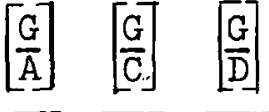

$1.761 .36 \quad 1.10$

$1.701 .32 \quad 1.06$ 
FIGURE 14

THEORE TICAL DYNAMIC

ULTIMATE YIELD STRESS vs.

RUPTURE DISC RATING

7500
6000



4500

4
4

9000

3000

500

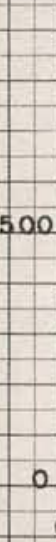

00

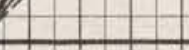

1500

3000

RUPTURE DISC RATING - PSI

LEGEND

$x$ Disc ruptured

b DISC DID NOT RUPTURE

- $45^{\circ}$ LINE

STAINLESS STEEL TYPE 304

NICKEL

COLD ROLL STEEL

PHOSPHOR BRONZE

I REGION IN WHICH DISC

WILL RUPTURE
III TION IN. WHICH DISC

II REGION IN WHCH DISC 


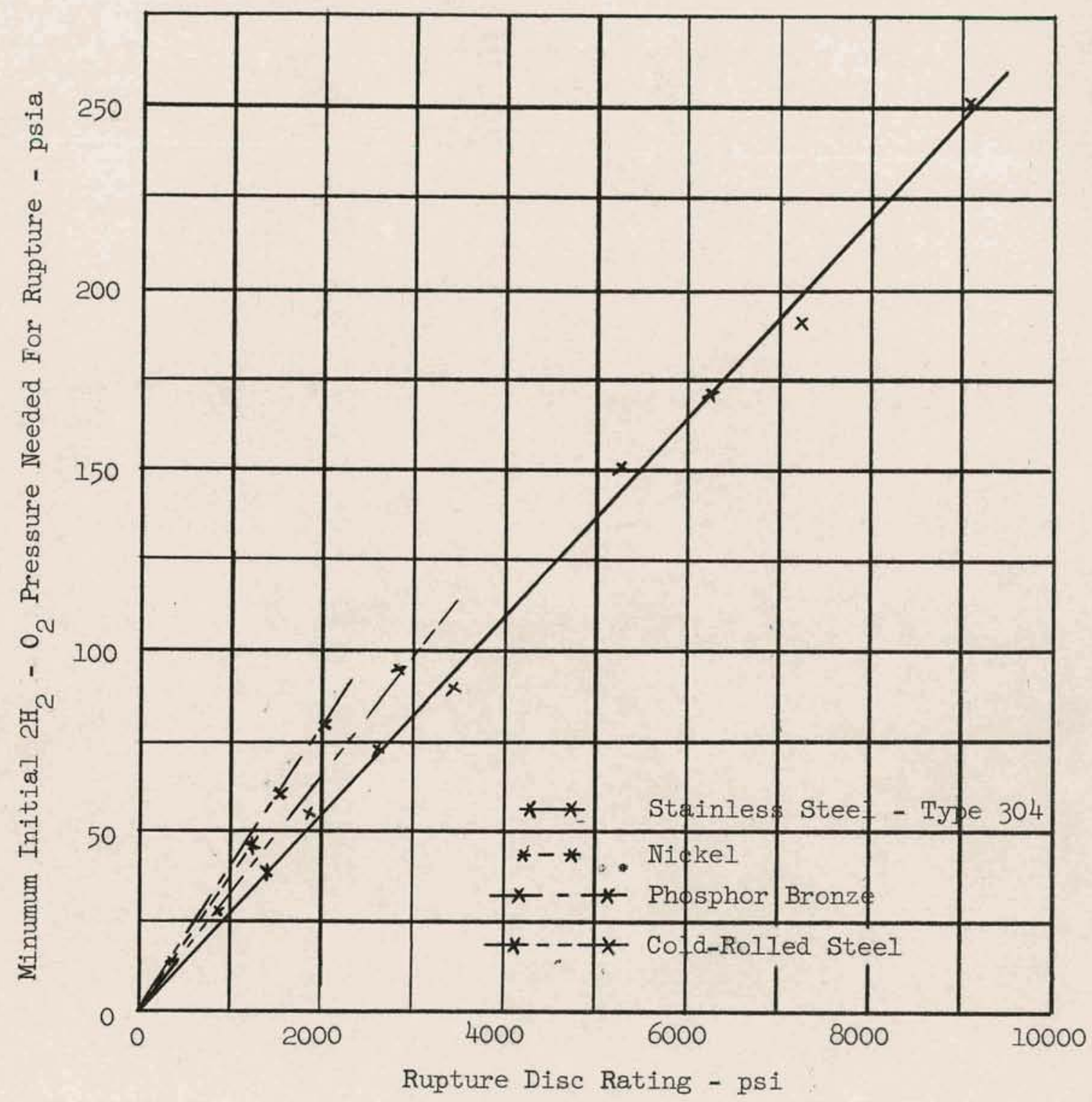

Figure 15: Initial Gas Pressure versus Rupture Disc Rating 


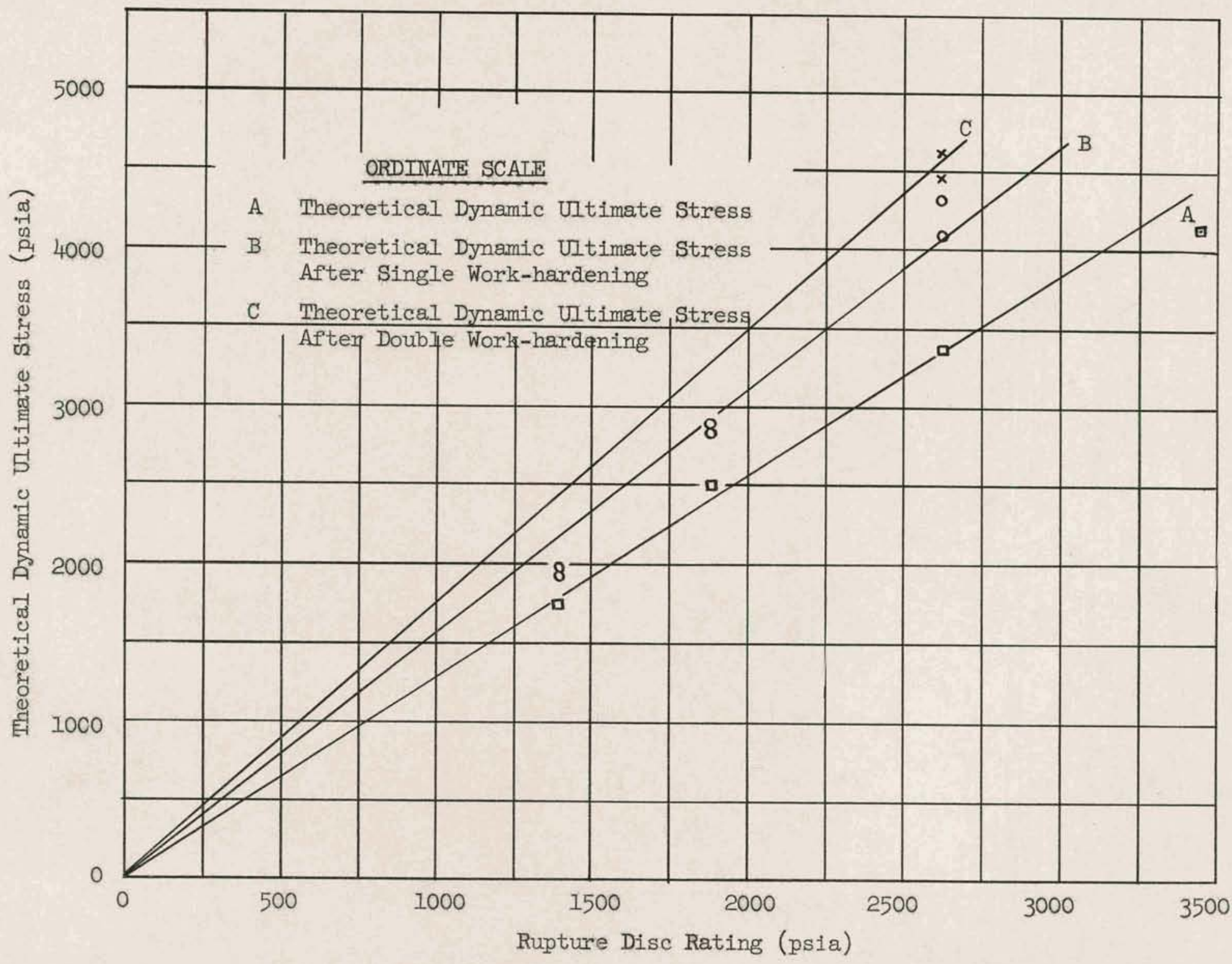

Figure 16: Effect of Work-Hardening upon the Dynamic UItimate Stress of Stainless 304 


\section{Discussion of Results}

A. Dynamic Ultimate Yield Stress

The dynamic ultimate yield stress was obtained for the following materials:

(1) Stainless Steel-Type 304

(2) Nickel

(3) Phosphor Bronze

(4) Cold-Rolled Steel.

The results of this study are tabulated in Table IV and are plotted in Figure 14. Table IV gives the dynamic ultimate yield stress in p.s.i.a. and as a function of the rupture disc rating. This function is equal to the ratio of the dynamic ultimate yield stress to the rupture disc rating. For stainless steel-type 304 , this function lies between 1.20 and 1.36, with the arithmetic average being 1.28. The ratios for nickel, phosphor bronze, and cold-rolled steel are 1.78, 1.79, and 1.50, respectively. The linear relationship presented in Figure 14 resulted in a correlation coefficient of 0.998 for stainless steel-type 304.

As can easily be seen from Figure 14, the theoretical dynamic ultimate yield stress is greater than the static ultimate: yield stress for all four materials tested. Phosphor bronze and nickel exhibited the largest percentage increase in the dynamic ultimate yield stress over the static ultimate yield stress with values of $78 \%$ and $74 \%$; respectively. Cold-rolled steel and 
stainless steel-type 304 exhibited smaller increases with values of $54 \%$ and $27 \%$, respectively.

Figure 15 illustrates the results obtained by employing the following parameters: (1) Minimum Initial $2 \mathrm{H}_{2}-\mathrm{O}_{2}$ Pressure Needed for Rupture; (2) Rupture Disc Rating. The graph is of value since the ratio between final detonation pressure (reflected) and initial gas pressure was not used in constructing this figure.

B. The Effect of Work-Hardening Upon the Dynamic Untimate Yield Stress The effect of work-hardening upon the dynamic ultimate yield stress is tabulated in Tables V and VI and is plotted in Figure 16 .

Phosphor bronze did not exhibit dynamic work-hardening, although phosphor bronze work-hardens statically. Nickel and cold-rolled steel showed an increase in the dynamic ultimate stress with the percentage increases being $33 \%$ and $39 \%$, respectively. Stainless steel-type 304 was exposed to both single and double work-hardening effects. Figure 16 shows in graphical form the relationship between the dynamic ultimate stress, dynamic ultimate stress with one work-hardening effect; and dynamic ultimate stress with a double.work-hardening effect and the rupture disc rating (static ultimate stress). From this graph, it can be seen that the dynamic ultimate stress increased with work-hardening. For one work-hardening effect.; the dynamic ultimate stress increased approximately $21 \%$. The dynamic ultimate s.tress was 
increased by $36 \%$ when the material was dynamically workhardened a second time. However, the value of the dynamic ultimate stress after a double work-hardening effect showed an increase of only $12 \%$ over the value of the dynamic ultimate stress after a single work-hardening effect. 
VI. Conclusions

(I) Materials under dynamic loading exhibit a higher ultimate yield stress than under static loading.

(2) The relationship between dynamic ultimate stress and static ultimate stress is linear.

(3) Stainless steel-type 304, nickel; and cold-rolled steel exhibit dynamic work-hardening.

(4) Phosphor bronze doe's not dynamically work-harden.

(5) Stainless steel-type 304 will progressively work-harden; thus, the dynamic ultimate stress will increase. However, each succeeding work-hardening will produce a smaller increase in the dynamic ultimate stress until fatigue of the material becomes the dominant factor. 
Appendix A

Experimental Data

Table VII

Determination of Dynamic Ultimate Yield Stress

\begin{tabular}{|c|c|c|c|c|}
\hline Run & $\begin{array}{c}\text { Disc } \\
\text { Rating } \\
\text { psi } \\
\end{array}$ & Material & $\begin{array}{c}\text { Initial } \\
\text { Gas } \\
\text { Pressure } \\
\text { psia } \\
\end{array}$ & Results \\
\hline 1 & 1390 & SS 304 & 44.7 & Fractured \\
\hline 2 & 1390 & SS 304 & 40.3 & Fractured \\
\hline 3 & 1390 & SS 304 & 36.1 & Did not fracture \\
\hline 4 & 1390 & SS 304 & 38.2 & Did not fracture \\
\hline 5 & 1390 & SS 304 & 39.2 & Did not fracture \\
\hline 6 & 1390 & SS $\cdot 304$ & 40.0 & Did not fracture \\
\hline 7 & 1390 & SS 304 & 40.2 & Did not fracture \\
\hline 8 & 1390 & SS $\cdot 304$ & 40.4 & Did not fracture \\
\hline 9 & 1390 & SS 304 & 41.1 & Fractured \\
\hline 10 & 1390 & SS 304 & 40.8 & Did not, fracture \\
\hline 11 & 1390 & SS 304 & $40 \cdot 9$ & Fractured \\
\hline 12 & .1390 & SS 304 & 36.6 & Fractured \\
\hline $4-4$ & 1390 & SS 304 & 38.2 & Fractured \\
\hline $4-5$ & 1390 & SS 304 & 38.2 & Fractured \\
\hline 13 & 1390 & SS 304 & 38.2 & Fractured \\
\hline 14 & 1390 & SS 304 & 35.9 & Did not fracture \\
\hline 15 & 1390 & SS 304 & 36.6 & Did not fracture \\
\hline 16 & 1390 & SS 30.4 & $37 \cdot 1$ & Did not fracture \\
\hline 17 & 1390 & SS 304 & 38.0 & Did not fracture \\
\hline 18 & 1390 & SS 304 & 38.4 & Fracturea \\
\hline 1 & 1880 & SS $\cdot 304$ & 53.0 & Did not fracture \\
\hline 2 & 1880 & SS. 304 & 53.2 & Did not fracture \\
\hline
\end{tabular}


Appendix A (Con't.)

Disc

Rating

$\underline{\text { Run }}$

3

4

5

6

7

14

15

16

.17

.18

19

20

1

2

3

4

6

7

8

9

.1

2

$3 \quad 3450$

$4 \quad 3450$

$5 \quad 3450$
Initial Gas

Pressure

Material

SS 304

SS 304

sS 304

SS. 304

SS 304

SS 30.4

SS 304

ŞS 304

SS 304

SS 304

SS 304

SS 304

SS 304

SS 304

SS 304

SS 304

SS 304

SS 304

SS 304

SS 304

SS 304

SS 304

SS 304

SS 304

SS 304

SS 304 psia

53.2

53.7

54.2

55.0

54.5

52.2

52.2

53.2

54.2

54.2

54.2

53.7

72

69

72

72

72

72

72.5

72.5

73.5

96

100

105

110

110
Results

Did not fracture

Did not fracture

Did not fracture

Fractured

Did not fracture

Fractured

Did not fracture

Dia not fracture

Fracture

Didinot fracture (Two discs in tube)

Fractured

Did not fracture

Fractured

Did not fracture

Did not fracture

Did not fracture

Did not fracture

Did not fracture

Did not fracture

Did not fracture

Fractured

Did not fracture.

Did not fracture

Did not fracture

Fractured

Fractured 
Appendix A (Con't.)

Disc

Rating

Run

6

7

8

9

10

11

.12

13

14

1 : 5280

. 5280

$3 \quad 5280$

$4 \quad 5280$

5. 5280

$6 \quad 5280$

$7 \quad 5280$

$8 \quad 5280$

$9 \quad 5280$

10

1

2

3

4

5

6

7 psi

3450

3450

3450

3450

3450

3450

450

5280

6240

6240

6240

6240

6240

6240

6240
Inttial Gas

Pressure

Material

SS 304

SS 304

SS 304

SS 304

SS 304

SS 304

SS 304

SS. 304

SS 304

SS 304

SS 304

SS. 304

SS 304

SS 304

SSS 304

SS: 304

SS 304

SS 304

SS 304

SS. 304

SS 304

SS 304

SS 304

SS 304

SS 304

SS 304 psia

105

102

100

95

90

85

88

87

89

152

146

141.

144

138

145

147

150

152.

151

172

168

166

.165

166

1.65

164
Results

Fractured

Fractured

Fractured

Fractured

Fractured

- Did not fracture

Did not fracture

Did not fracture

Did not fracture

Fractured

Fractured

Did not fracture

Fractured

Did not fracture

Did not fracture

Did not fracture

Did not fracture

Fractured

Did not fracture

Fractured

Fractured

Did not fracture

Did not fracture

Fractured

Did not fracture

Did not fracture 
Appendix A (Con't.)

Disc

Rating

. Run

8

9

10

.11

1

2

3

4

5

6

7

.8

9

10

11

12

13

14

1

2

3

4

5

6

1

2

psi

6240

6240

6240

6240

7240

7240

7240

7240

7240

7240

7240

7240

7240

7240

7240

7240

7240

7240

9100

9100

9100

9100

9100

9100

340

340
Initial Gas

Pressure

Material

SS 304

SS 304

SS. 304

SS 304

SS. 304

SS 304

SS. 30.4

SS 304

SS 304

SS. 304

SS 304

SS 304

SS 304

SS 304

SS 304

SS. 304

SS 304

SS. 304

SS. 304

.SS. 304

SS . 304

SS . 304

SS 304

SS 304

N.

N psia

166

167

168

170

201

196

191

193

192

190

188

189

.185

184

183

185

186

188

253

248

253

250

251

249

.12. 1

14.7
Results

Did not fracture

Did not fracture

Did not fracture

Did not fracture

Fractured

Fractured

Did not fracture

Fractured

Fractured

Fractured

Did not fracture

Did not fracture

Fractured

Did not fracture

Did not fracture

Did not fracture

Did not fracture

Did not fracture

Fractured

Did not fracture

Fractured

Did not fracture

Fractured

Did not fracture

Did not fracture

Fractured 


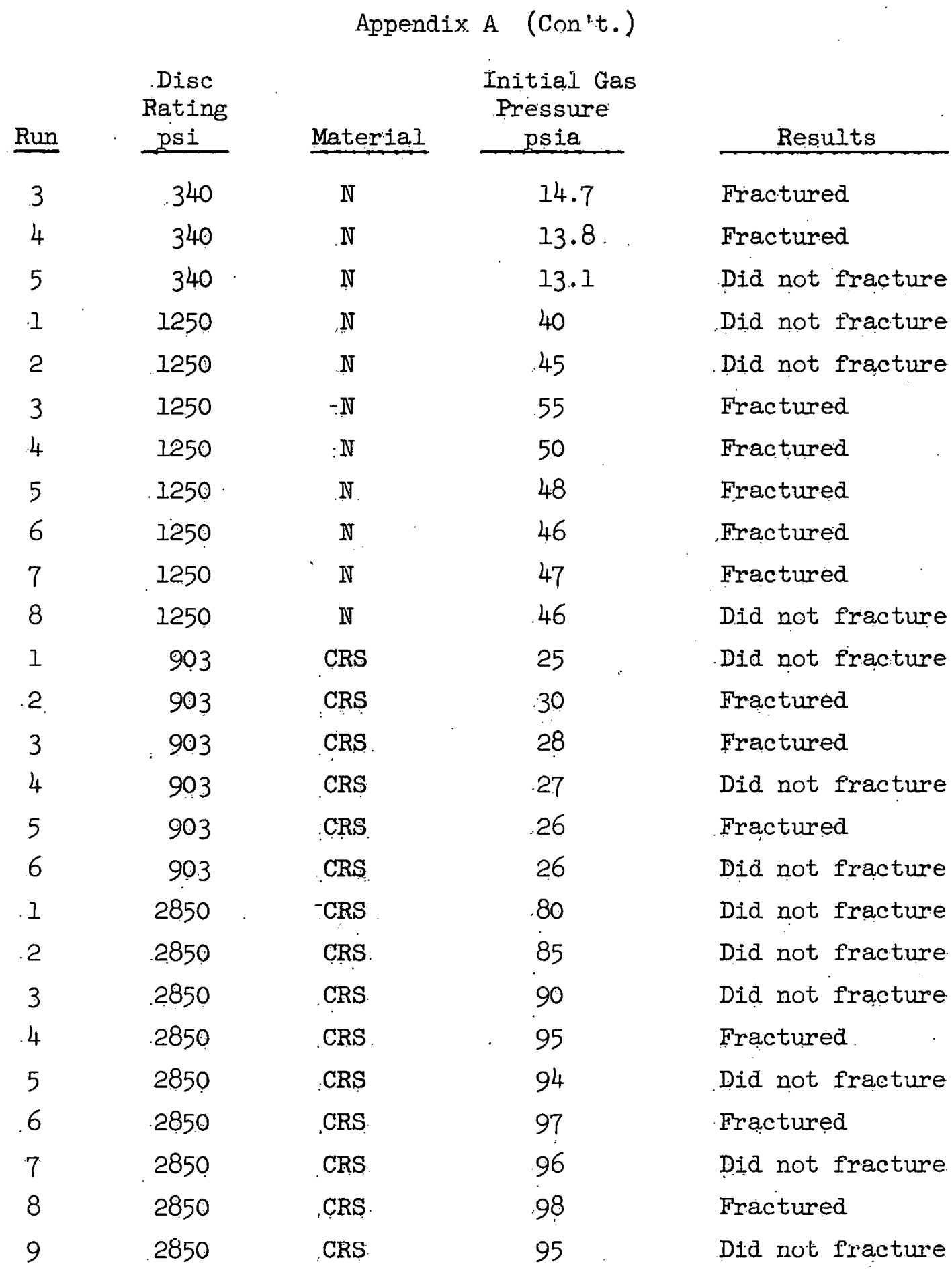




\begin{tabular}{|c|c|c|c|c|}
\hline Run & $\begin{array}{c}\text { Disc } \\
\text { Rating } \\
\text { psi }\end{array}$ & Append & $\begin{array}{l}\text { A (Con't.) } \\
\text { Initial Gas } \\
\text { Pressure } \\
\text { psia }\end{array}$ & Results \\
\hline 1 & 1540 & $\therefore$ P.B. & 60 & Fractured \\
\hline 2 & 1540 & P.B. & 50 & Did not fracture \\
\hline 3 & 1540 & P.B. & 55 & Did not fracture \\
\hline 4 & 1540 & P.B. & 57 & Did not fracture \\
\hline 5 & .1540 & P.B. & 59 & Did not fracture \\
\hline 6 & 1540 & P.B. & 61 & Fractured \\
\hline 1 & 2070 & P.B. & 60 & Did not fracture \\
\hline 2 & 2070 & P.B. & 65 & Did not fracture \\
\hline 3 & 2070 & P.B. & 70 & Fractured \\
\hline 4 & 2070 & P.B. & 67 & Diạ not fracture \\
\hline 5 & 2070 & P.B. & 69 & Did not fracture \\
\hline 6 & 2070 & P.B. & 71 & Did not fracture \\
\hline 7 & 2070 & P.B. & 73 & Did not fracture \\
\hline 8 & 2070 & P.B. & 75 & Did not fracture \\
\hline 9 & 2070 & $P . B$ & 80 & Fractured \\
\hline 10 & 2070 & P.B. & 77 & Did not fracture \\
\hline
\end{tabular}


Appendix A

Experimental Data

Determination of the Effect of Work-Hardening on the Dynamic Ultimate Yield Stress

\begin{tabular}{|c|c|c|c|c|c|}
\hline Run & $\begin{array}{c}\text { Disc } \\
\text { Rating } \\
\text { psi }\end{array}$ & Material & $\begin{array}{l}\text { Initial } \\
\text { Loading } \\
\text { psia } \\
\end{array}$ & $\begin{array}{l}\text { Final } \\
\text { Loading } \\
\text { psia } \\
\end{array}$ & Results \\
\hline $19-3$ & 1390 & SS 304 & 36.1 & 39.1 & Did not fracture \\
\hline 20 & 1390 & SS 304 & 36.1 & 40.4 & Did not fracture \\
\hline 25 & 1390 & SS 304 & 36.1 & 45.0 & Fractured \\
\hline 26 & 1390 & SS 304 & 36.1 & 43.0 & Fractured \\
\hline 21 & 1390 & SS 304 & 34.6 & 42.7 & Did not fracture \\
\hline 22 & 1390 & SS 304 & 34.6 & 47.2 & Fractured \\
\hline 23 & 1390 & SS 304 & 34.6 & 45.0 & Fractured \\
\hline 24 & 1390 & SS 304 & 34.6 & 44.0 & Fractured \\
\hline 27 & 1390 & SS. 304 & 34.6 & 43.0 & Fractured \\
\hline 28 & .1390 & SS 304 & 34.6 & 42.5 & Fractured \\
\hline 29 & 1390 & SS 304 & 34.6 & 42.0 & Fractured \\
\hline $8-1$ & 1880 & SS 304 & 52 & 65 & Fractured \\
\hline 9 & 1880 & SS 304 & 52 & 62 & Fractured \\
\hline 10 & 1880 & SS 304 & 52 & 60 & Fractured \\
\hline 11 & .1880 & SS 304 & 52 & 50 & Did not fracture \\
\hline $21-15$ & 1880 & SS 304 & 52 & 58 & Did not fracture \\
\hline 22. & 1880 & SS 304 & 52 & 59.5 & Did not fracture \\
\hline 23 & .1880 & SS 304 & 52 & 62 & Did not fracture \\
\hline 24 & .1880 & SS 304 & 52 & 65 & Fractured \\
\hline 12 & 3880 & SS 304 & 49 & 60 & Did not fracture \\
\hline 13 & 1880 & SS 304 & 49 & 62 & Fractured \\
\hline 25 & 1880 & SS 304 & 49 & 59 & Did not fracture \\
\hline 26 & .1880 & SS .304 & 49 & 63 & Fractured \\
\hline
\end{tabular}


Appendix A (Con't.)

\begin{tabular}{|c|c|c|c|c|c|}
\hline Run & $\begin{array}{c}\text { Disc } \\
\text { Rating } \\
\text { psi } \\
\end{array}$ & Material & $\begin{array}{l}\text { Initial } \\
\text { Loading } \\
\text { psia }\end{array}$ & $\begin{array}{c}\text { Final } \\
\text { Looiding } \\
\text { psia } \\
\end{array}$ & Results \\
\hline 10 & 2620 & SS 304 & 69 & 74 & Did not fracture \\
\hline $11-2$ & 2620 & SS 304 & 69 & 75 & Did not fracture \\
\hline 12 & 2620 & SS 304 & 69 & 76 & Did not fracture \\
\hline 13 & 2620 & SS 304 & 69 & 78 & Did not fracture \\
\hline 14 & 2620 & SSS 304 & 69 & 80 & Did not fracture \\
\hline 15 & 2620 & SS 304 & 69 & 82 & Did not fracture \\
\hline .16 & 2620 & SS 304 & 69 & 84 & Did not fracture \\
\hline 17 & 2620 & SS 304 & 69 & 89 & Did not fracture \\
\hline 18 & 2620 & SS 304 & 69 & 95 & Fractured \\
\hline 19 & 2620 & SS 304 & 60 & 95 & Fractured \\
\hline 20 & 2620 & SS 304 & 60 & 90 & Fractured \\
\hline 21 & 2620 & SS 304 . & 60 & 85 & Did not fracture \\
\hline 6 & 340 & $\mathbb{N}$ & 12.1 & 19.7 & Fractured \\
\hline 7 & 340 & . & 12.1 & 14.7 & Did not fracture \\
\hline 8 & 340 & N & 12.1 & $17 \cdot 7$ & Did not fracture \\
\hline 9 & 340 &. $\mathbb{N}$ & 12.1 & 18.7 & Fractured \\
\hline 7 & 903 & CRS & 24 & 30 & Did not fracture \\
\hline 8 & 903 & CRS & .24 & 35 & Did not fracture \\
\hline 9 & 903 & CRS & 24 & 40 & Fractured' \\
\hline 10 & 903 & CRS. & 24 & 38 & Did not fracture \\
\hline 7 & 1540 & P.B. & 54 & 65 & Fractured \\
\hline 8 & 1540 & P.B. & 54 & 60 & Did not fracture \\
\hline 9 & 1540 & P. B. & 54. & 63 & Fractured \\
\hline 10 & 1540 & P.B. & 54 & 61 & Fractured \\
\hline
\end{tabular}




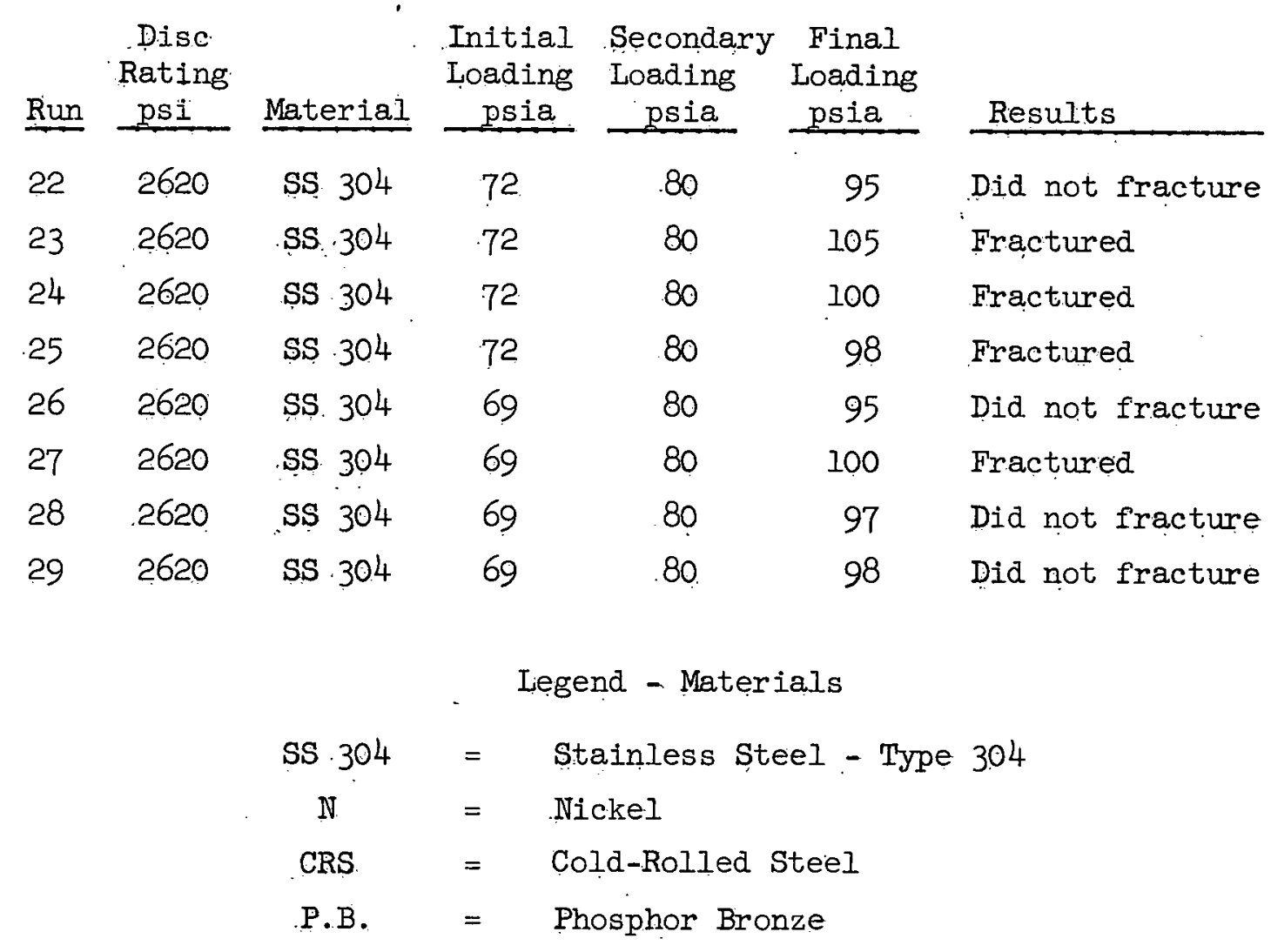


Appendix B

'Determination of the Theoretical Reflected Wave (Detonation) Pressure In this investigation dynamic loads were applied to rupture discs by subjecting the discs to the impact of a detonation wave. In order to calculate the applied dynamic load it was necessary to establish the reflected detonation wave pressures which result from detonating dry stoichiometric hydrogen-oxygen mixturés.

McGlll and Luker ${ }^{l}$ in an unpublished investigation calculated the theoretical incident detonation wave pressures which resulted from the detonation of dry stoichiometric hydrogen-oxygen mixtures. The calculations were made for an initial pressure range of 1 - 150 atmospheres. Figure 17 shows the calculated theoretical incident detonation wave pressures from this investigation. In the range of 0 to 20 atmospheres the correlation presented in Figure 17 may be represented by the following equation:

$$
I=\mathrm{AP}
$$

where $I=$ incident wave pressure atmospheres

$P=$ initial dry gas pressure

$A=$ slope of line $=20.2$

McGill and Luker also calculated the ratio of the final theoretical reflected detonation wave pressure to the initial gas pressure at an initial gas pressure of one atmosphere. This ratio, $\beta$, was calculated theoretically to be 42.64 . If the calculated

1 McGill, Paul and Luker, J. A., Syracuse University Research Institute. 
reflected wave pressure is divided by the calculated incident wave pressure at one atmosphere, a ratio, $\theta$, of 2.36 is obtained.

The calculated incident wave pressures of McGill and Luker were multiplied by this value of $\theta$, which was determined for a one atmosphere detonation. The results of this calculation as shown in Figure 18 yielded a straight line with a slope of 46.5 . Thus, if the assumption that $\theta$ is constant over the range $0-20$ atmospheres initial pressure is correct, the final theoretical reflected wave pressure may be obtained by multiplying the initial dry gas pressure by 46.5 .

Macafee, in an unpublished investigation: ${ }^{1}$ obtained additional data which confirm that $\beta$ (theoretical reflected detonation wave pressure/initial dry gas pressure) is approximately constant over the entire initial pressure range of 0 - 20 atmospheres. Macafee measured $\beta$ experimentally in a shock tube using a pressure transducer. While Macafee's value of $p,(36)$ was lower than the calculated theoretical at one atmosphere, $\beta$ was determined to be constant over the entire pressure range investigated. Macafee's experimental data resulted in a correlation coefficient of 0.945 .

From the work of McGill, Luker and Macafee it was concluded that over the initial pressure range 0 - 20 atmospheres the theoretical incident wave pressure and the reflected wave pressure are simple multiples of the initial dry gas pressure.

1 Macafee, Jr., Irvin, Syracuse University Research Institute Report No. Ch.E. 273-556F4, July 1, 1956. 
In this investigation it was decided to use the theoretical determined value of $\beta$ rather than the measured value. Thus, the theoretical reflected detonation pressure was calculated by multiplying the initial dry gas pressure by 46.5 . This theoretical reflected pressure would be the maximum pressure which could be developed by a detonation since. McG̣ill and Luker assumed equilibrium was obtained in making their calculations.

While this theoretical reflected wave pressure may be somewhat higher than reflected pressures actually obtained in practice, it does however provide an excellent theoretical standard for use in comparing dynamic and static loading. 


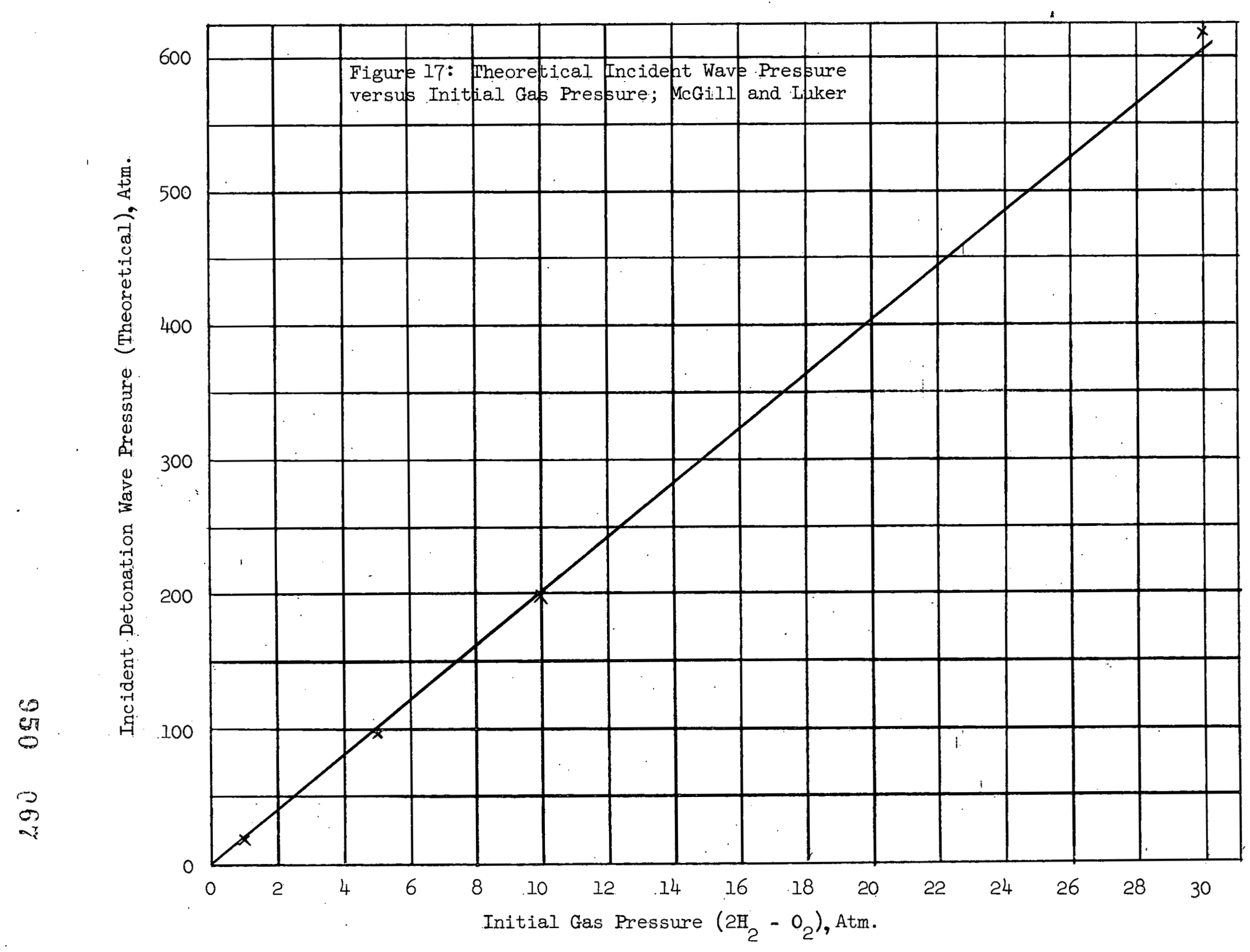




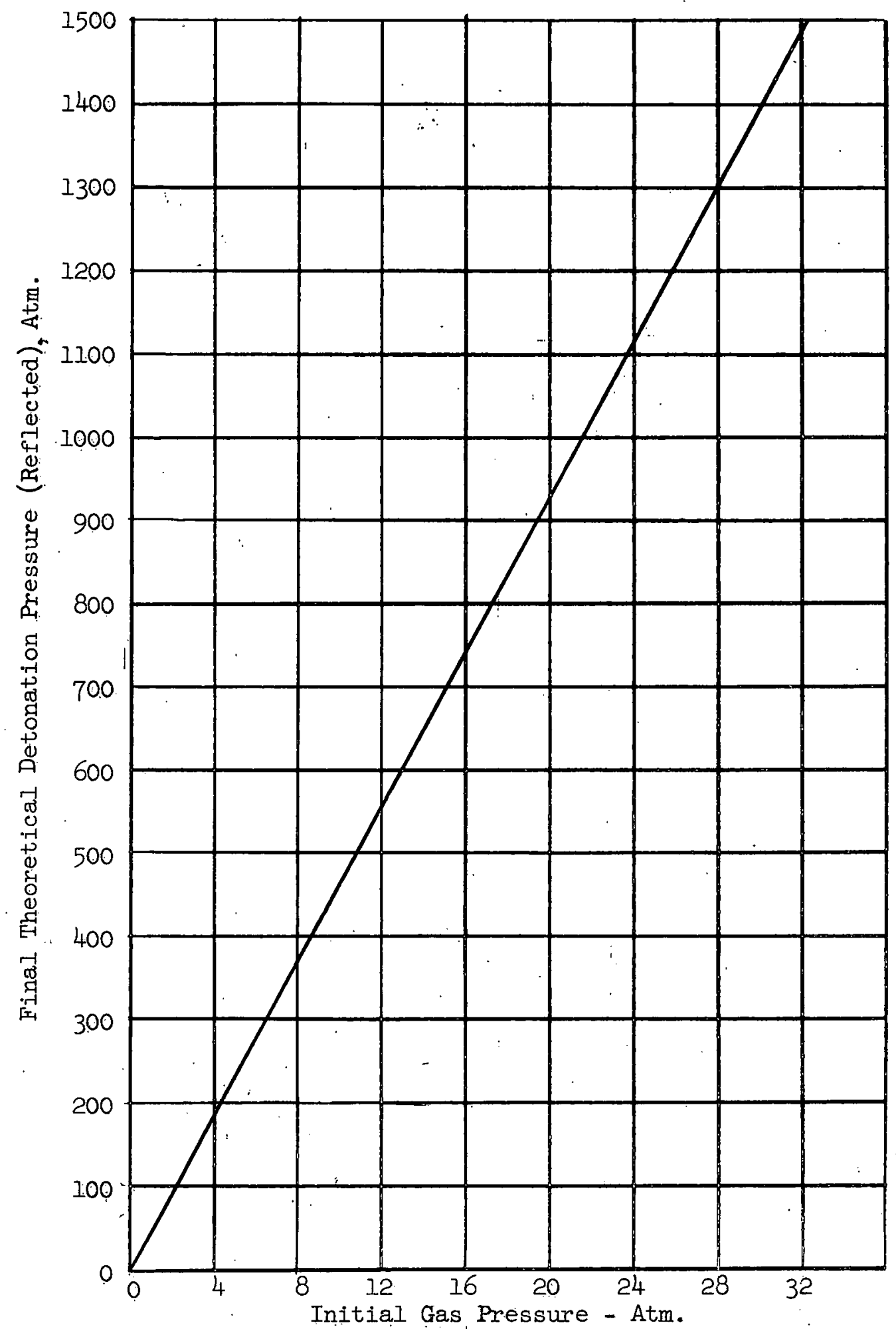

Figure 18: Final Theoretical, Detonation

Pressure versus Initial Gas Pressure 
Appendix C
Rupture Discs - Before and After a Detonation

Figures 19-30 are photographs taken of actual rupture discs before and after a detonation. There are two complete sequences of discs.

Figures 19-22 and 23-26 show the effect caused by increasing the final detonation pressure. The sets of discs are rated statically at 9100 and 3450 psi. Figures 19 and 23 show discs before a detonation with relative heights of 3.4 . The discs in Figures 20 and 24 show relative heights of 5.1 and $4.3 \%$ respectively, while the discs in Figures 22 and 26, which were exposed to the greatest impact, showed relative heights of 5.8 and 4.9 , respectively. As can be seen from each sequence, the magnitude of the deformation increases with increasing final detonation pressure.

In Figures 27-30, the photographs show three different types of fractures that could occur if the final detonation pressure was equal to or greater than the dynamic ultimate yield stress. The center of the disc in Figure 30 was completely sheared off, leaving the outside rim. Figure 29 shows the fracture that was prevalent in this investigation.

In only one instance did fracture of the type shown in Figure 27 occur. In this case, the fracture was a pinhole in the center of the disc. A profile view of the same disc can be seen in Figure 28.

The magnification was $3 x$ in all photographs. 


\section{4}

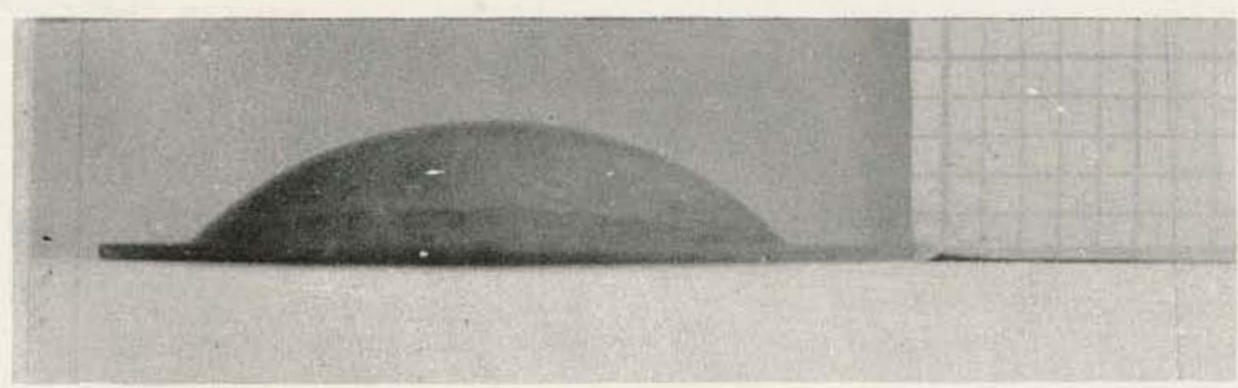

Figure 19: Rupture Disc - Stainless Steel 304 Rating - 9100 psi

Final Detonation Pressure - 0 psia

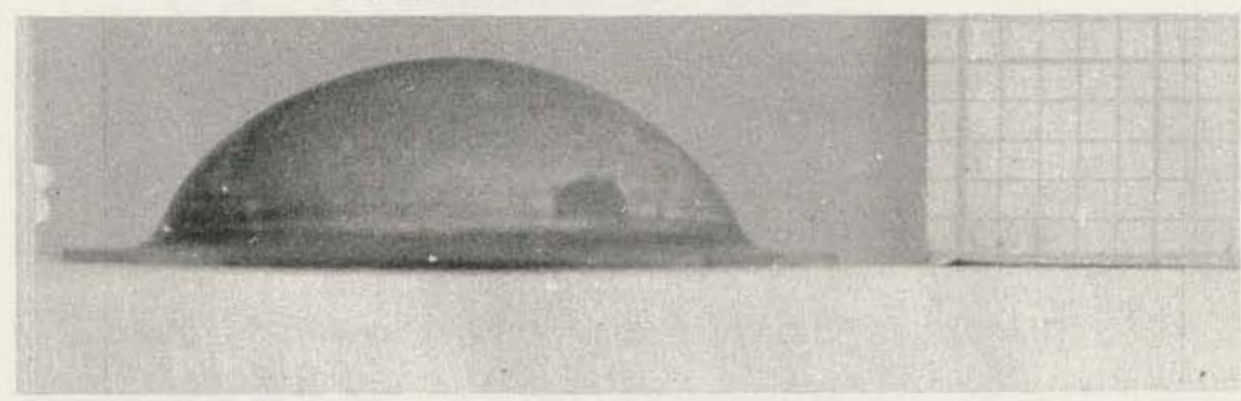

Figure 20: Rupture Disc - Stainless Steel 304 Rating - 9100 psi

Final Detonation Pressure - 11,530 psia

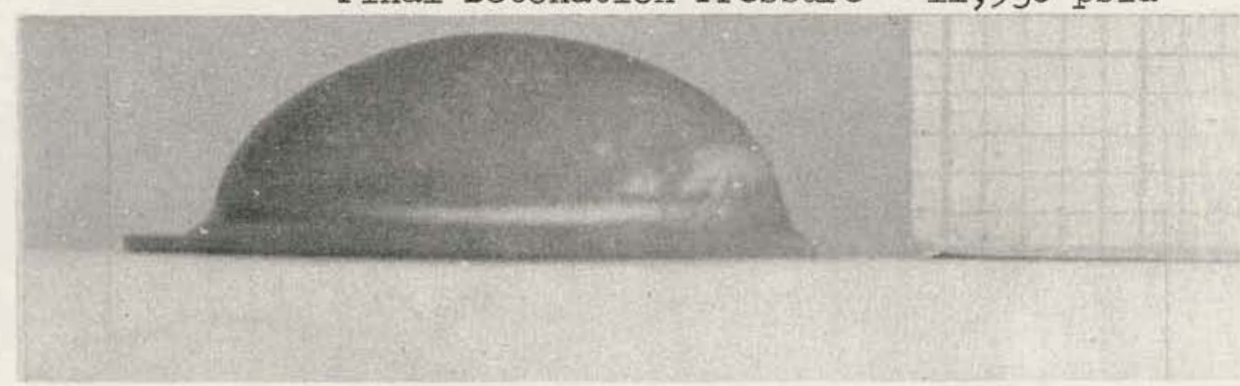

Figure 21: Rupture Disc - Stainless Steel 304 Rating - 9100 psi

Final Detonation Pressure - 11,580 psia

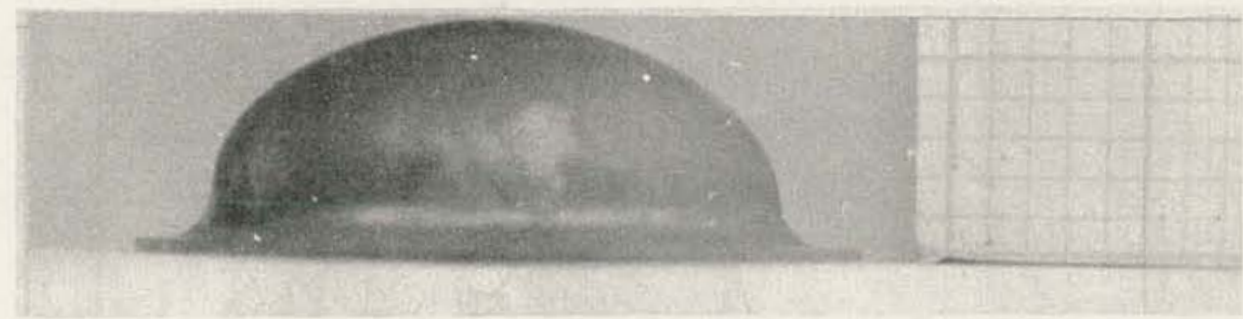

Figure 22: Rupture Disc - Stainless Steel 304 Rating - 9100 psi

Final Detonation Pressure - 11,630 psia 


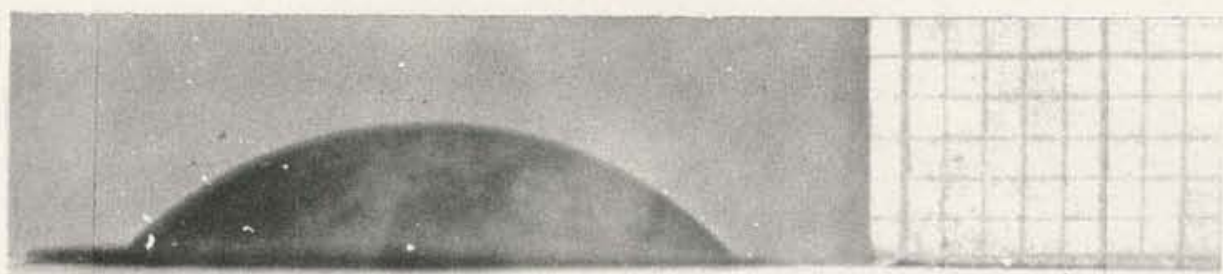

Figure 23: Rupture Disc - Stainless Steel 304 Rating - 3450 psi

Final Detonation Pressure - 0 psia

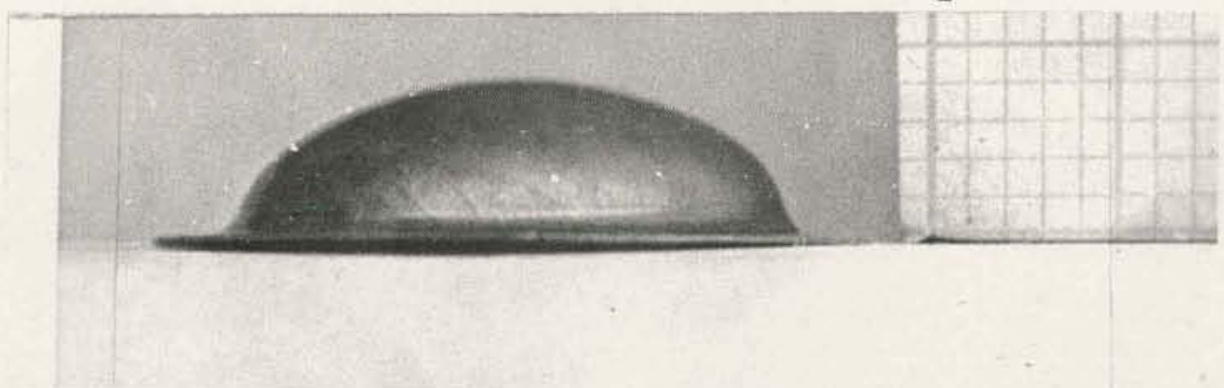

Figure 24: Rupture Disc - Stainless Steel 304 Rating - 3450 psi

Final Detonation Pressure - 3950 psia

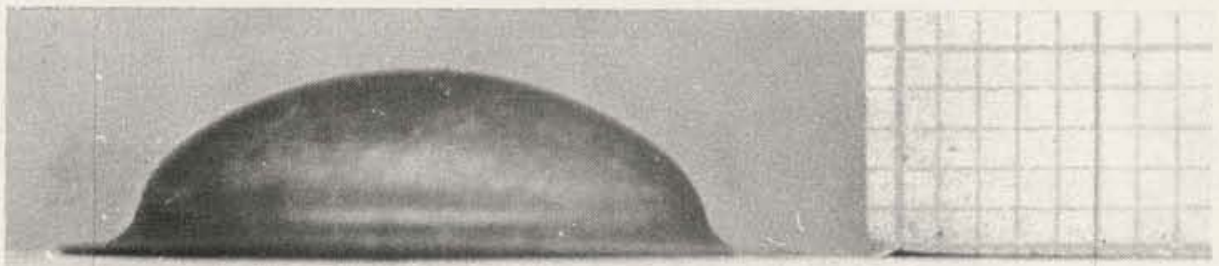

Figure 25: Rupture Disc - Stainless Steel 304

Rating - 3450 psi

Final Detonation Pressure - 4050 psia

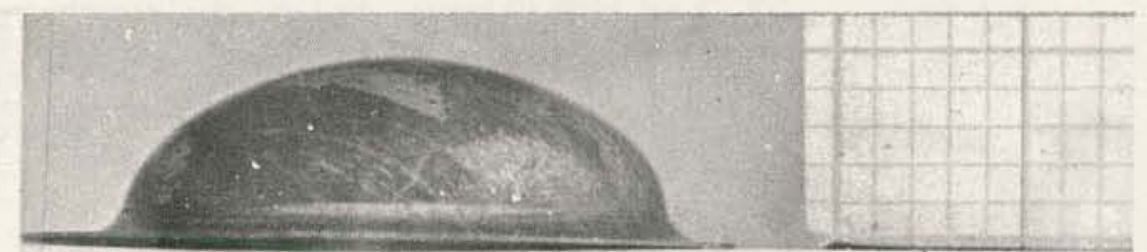

Figure 26: Rupture Disc - Stainless SteeI 304

Rating - 3450 psi

Final Detonation Pressure - 4090 psia 
Figures 27 and 28: Rupture Disc Nickel Rating - 1250 psi

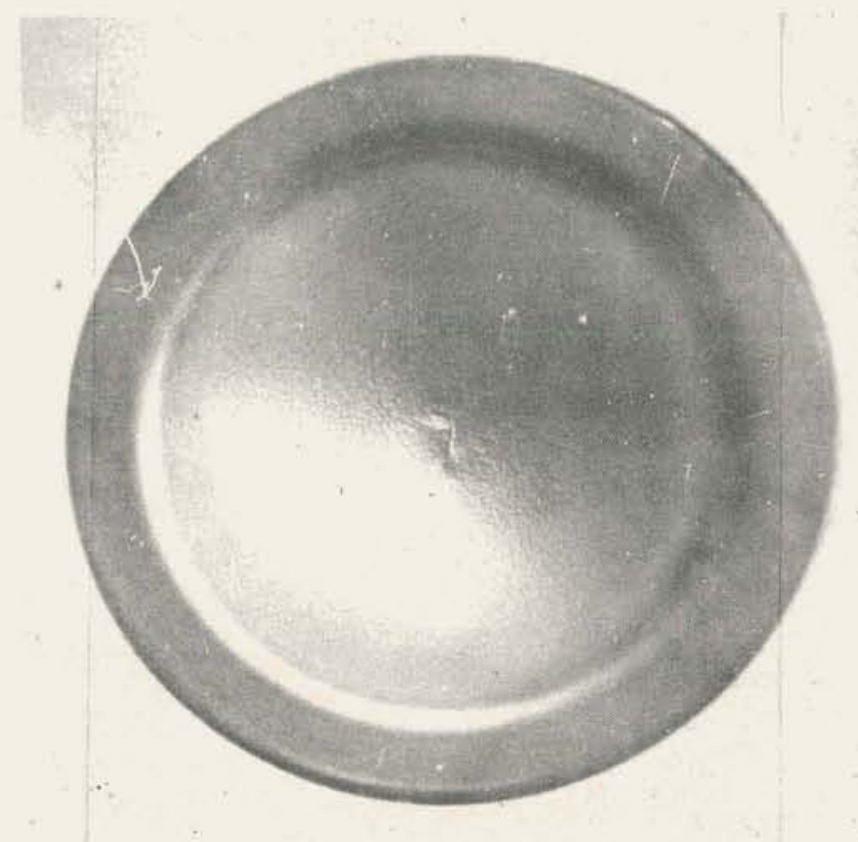

Final Detonation Pressure - 2140 psia

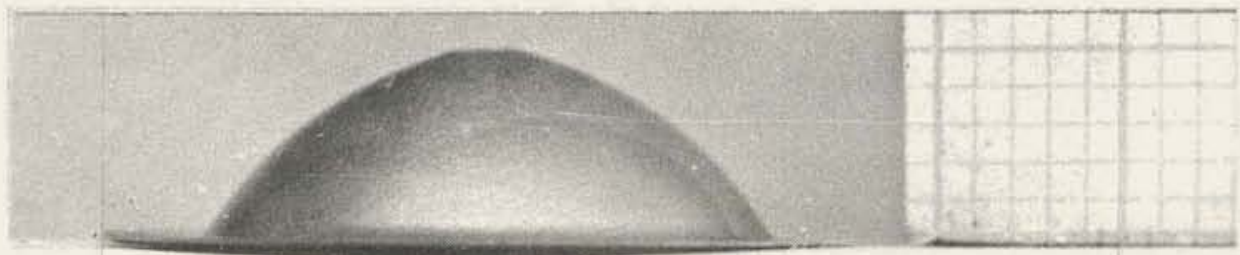

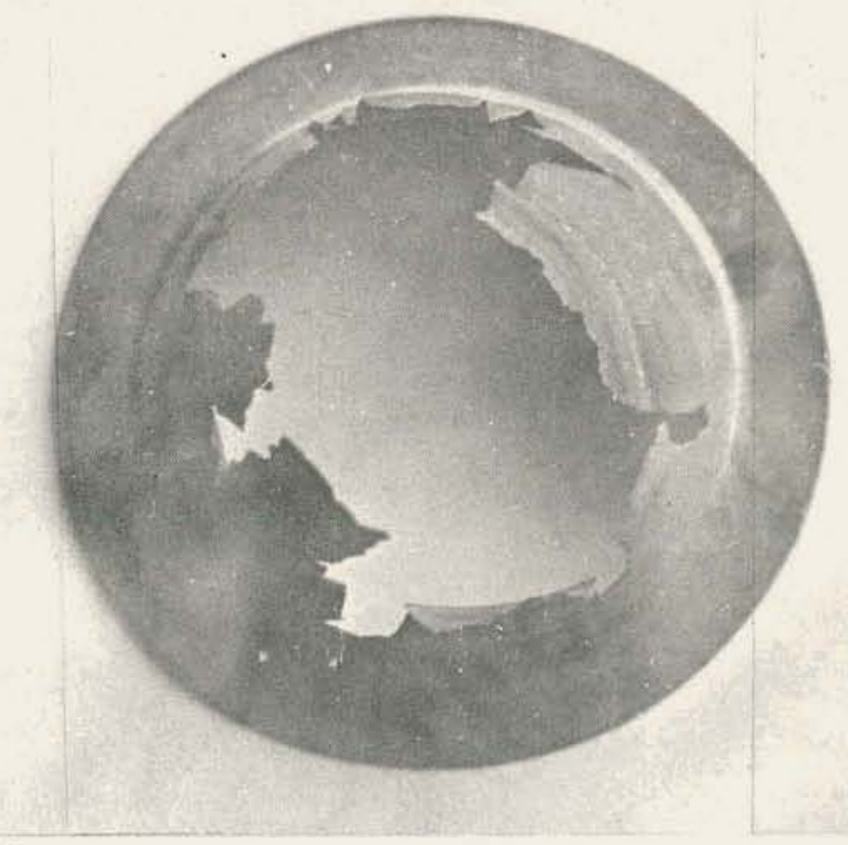

Figure 29: Rupture Disc - Nickel Rating - 1540 psi F. D. P. - 2840 psia

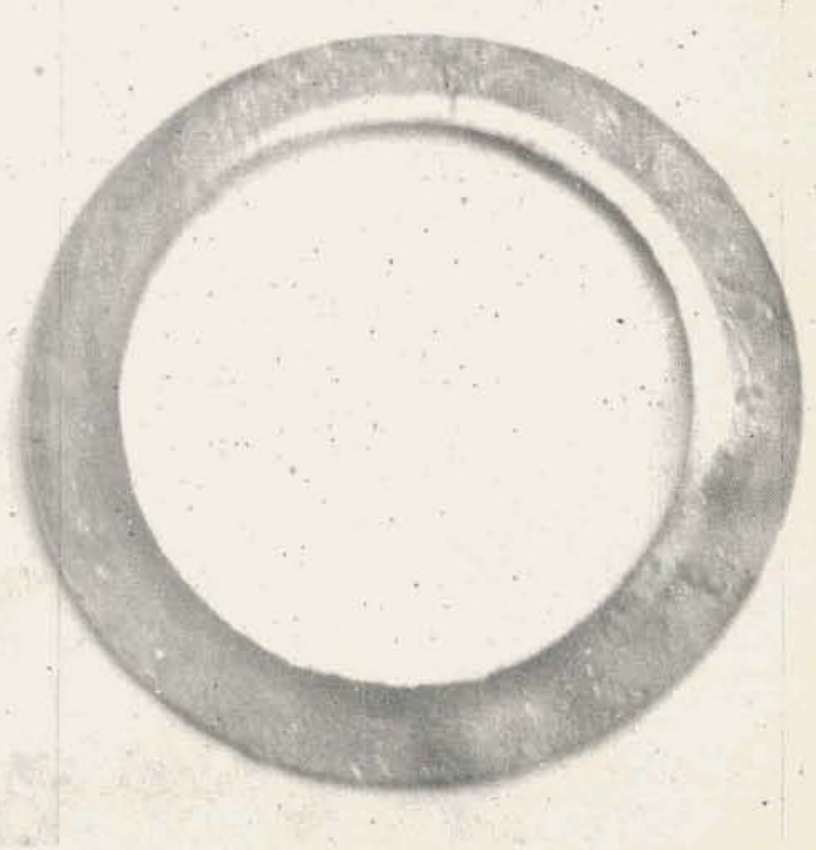

Figure 30: Rupture Disc - C. R. Steel Rating - 2850 psi

F. D. P. - 4560 psia 


\section{TABLE VIII}

Composition of Stainless Steel-Type 304, Phosphor Bronze, Nickel, and Cold-Rolled Steel

Percent Composition

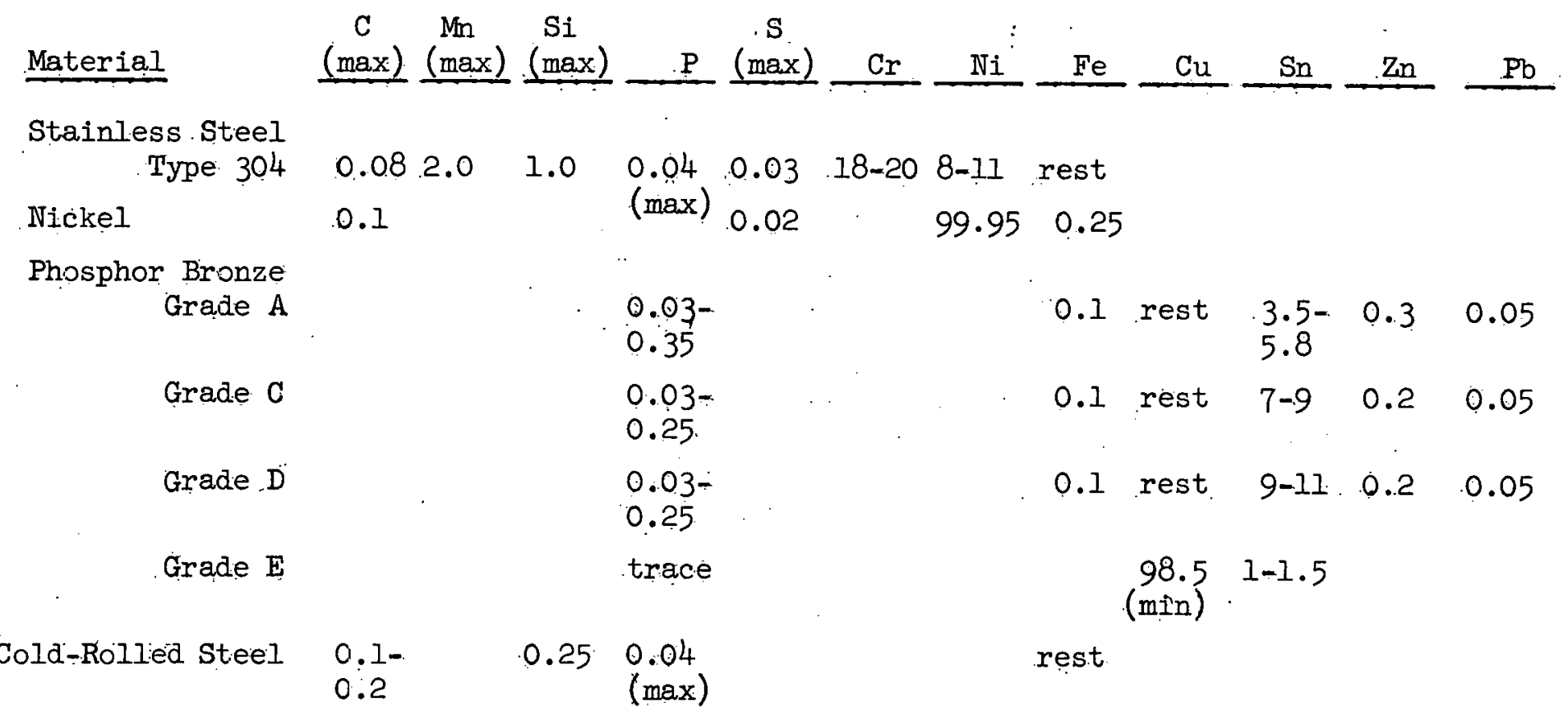

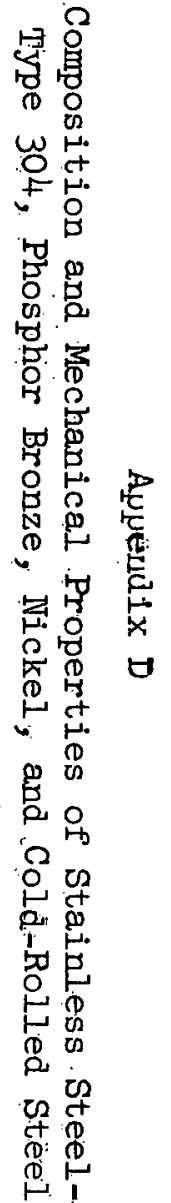


Appendix D (cont.)

TABLE TXX

Mechanical Properties of Stainless Steel-Type 304,

Phosphor Bronze, Nịckel, and Cold-Rolled Stëel

\begin{tabular}{|c|c|c|c|}
\hline Material & $\begin{array}{c}\text { Tensile Strength } \\
\text { psï }\end{array}$ & $\begin{array}{c}\text { Yield Strength } \\
\text { psi }\end{array}$ & $\begin{array}{l}\text { Percent Elongation } \\
\text { in two (2) inches }\end{array}$ \\
\hline $\begin{array}{r}\text { Stainless Steel } \\
\text { Type } 304\end{array}$ & 85000 & $30-35000$ & 70 \\
\hline Nickel & 46000 & 8500 & 30 \\
\hline Cold-Rolled Stëel & 47000 & 26000 & 35 \\
\hline $\begin{array}{l}\text { Phosphor Bronze } \\
\text { Grade A }\end{array}$ & & & \\
\hline annealed & 47000 & 19000 & 64 \\
\hline 1/2 hard & 68000 & 55000 & 28 \\
\hline hard. & 81000 & 75000 & 10 \\
\hline $\begin{array}{l}\text { Grade C } \\
\text { annealed }\end{array}$ & 55000 & $-\ldots$ & 70 \\
\hline$I / 2$ hard & 76000 & 55000 & 32 \\
\hline hard & 93000 & 72000 & 10 \\
\hline $\begin{array}{l}\text { Grade D } \\
\text { annealed }\end{array}$ & 66000 & $\cdots$ & 68 \\
\hline I/2 hard & 83000 & $\ldots$ & 32 \\
\hline hard & 100000 & $\ldots$ & 13 \\
\hline $\begin{array}{l}\text { Grade. E } \\
\quad \text { annealed }\end{array}$ & 40000 & 14000 & 48 \\
\hline 1/2 hard & 55000 & .45000 & 16 \\
\hline hard & 65000 & 50000 & 8 \\
\hline
\end{tabular}




\section{Bibliography}

1. Baylston, H. M., "An Introduction to the Metaliurgy of Iron and Steel", John Wiley and Sons, Inc., New York, Second Edition (1936).

2. Barrett, C. S., "Structure of Metals: Crystallographic Methods, Principles, and Data", McGraw-Hill Book Co.y Inc.y New York (1952).

3. Boa's, W., and Schmid, E., Z. Physik, 71,.703 (1931).

4. Campbeil, C.., Littler, W. B., and Whitworth, C., "Measurements of Pressures Developed in Explosion Waves", Proc. Roy. Soc. Iond., Al37, 380 (1932).

5. Chalmers, B., Proc. Roy. Soc. Lond., Al62, 120 (1937).

6. Clark, D. S., and Duwez, P. E., "Discussion of the Forces Acting in Tension Impact Tests of Materials", J. App. Mech., 15, No.3; $243-47(1940)$.

7. Clark, D. S., and Wood, D. S., "The Tensile Impact Properties of Some Alloys", Iron A. Soc. Metals, 42, 45 (1950).

8. Coonain, Fo. L., "Principles of Physical Metallurgy", Harper Brothers., Nèw York.

9. Elam, C. F., "The Influence of the Rate of Deformation on the Tensile Test with Special Reference to the Yield Point in Iron and Steel", Proc. Roy. Soc. Lond. A165, 568-93 (1938).

10. Gensamier, M., Pearsall, E. B., and Smith, G. V., Trans. ASM, 28., 386 (1940).

11. Gensamer, M. y Pearsall, . F. B., Pellini, W. S.,y and Law, J. R., Jr., "The' Tensile Properties of Perlite, Bainite, and Spheroidite", Trans. ASM, 30, 983 (1942).

12. Gernstein, M., Carlson, E. R.,y and Hilï, F.'V., "Natural Gas-Air Explosions at Reduced Pressures; Detonation Velocities and Pressures", Ind. Fng. Chem o, 46, 2558-62 (1954)。

13. Gordon, W. E... "Studies of Gaseous Detonations"y. Ph. D. Thesis, Harvard University (1943). 
14. Harris, D. B., and White, M. P., "Compartson of the Hardening Produced in a Yield Point Steel by Uniaxial Loading under Compression Impact", J。 App. Mech., 21, 194 (1954)。

15. Mann, $\mathrm{H}_{0} \mathrm{C}_{0}$, "The Relation Between the Tension, Static, and Dynamic Tests"; Proc. ASTM, 35, Part II, 323 (1935)。

16. Mann, H. C., "High Velocity Tension Impact Test", Proc. ASTM, 36, Part II, 85 (1936)。

17. Matt, No Fo, "Mechanical Properties of Metals", Physica, I5, 119 (1949).

18. Murphy, T.S., Jro: "Rupture Diaphragms: Characteristics, Úses, and Size CaIculations" Chem. Eng.\%. 51, No. 11, 108-12 (1955).

19. Rinehart, J. S., "Work-hardening of Mild steel by Explosive Attack", J。 App. Phys., 22, 1086-7 (1951)。

20. Sachs, G., "Fundamentals of the Workings of Metals".' Pergamon Press, Ltd., London, 1954.

21. Schmid, E.y.z. Elektrochem.y 37y, 447 (I931)。

22. Stewart, P. B.y and Fox, R. T., Jr., "Aluminum Foil Rupture Discs offer Low-Cost protection", Chem. Eng. Prog.y 22, No. 3y II5M (I956).

23. Tabor, J., "The Hardness of Metals", Clarendon Press, Oxford, I95I.

24. White, M. Pog "On the Impact Behavior of Metal with a Yield Point", J. App.Mech。 16, 39 (1949).

25. Zwikker, C.; "Physical Properties of Solid Materials", Interscience Publishers, Inc o, New York, 1954。 
(4)

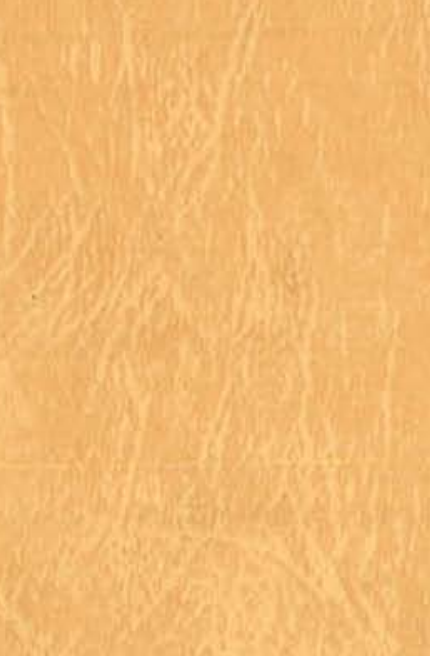

whe
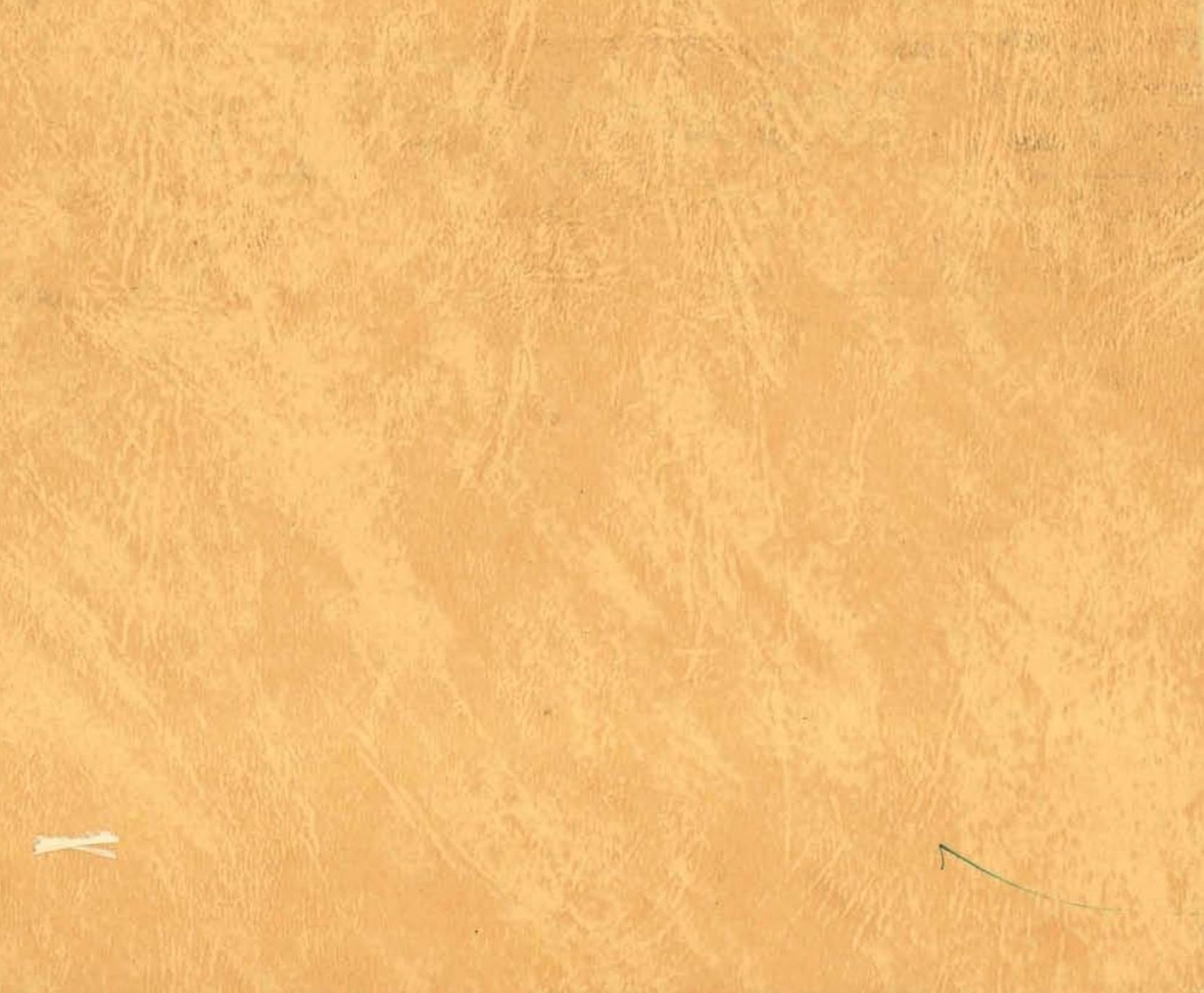